\begin{abstract}
Little is known about the nature of adolescents' experiences of Technology-Assisted Adolescent Dating Violence and Abuse (TAADVA) behaviours and whether the Electronic Communication Technology (ECT) used varies depending on the behaviour. This paper therefore examines the nature of adolescents' victimisation experience of 12 different TAADVA behaviours via nine methods of ECT (phone call, text, instant messenger, social networking site, picture message, video chat, email, chatroom, and website/blog). Four-hundred-and-sixty-nine 12-18 year old British adolescents (59\% ( $n$ $=277$ ) of which had dated in the last year) completed a questionnaire regarding their experience of TAADVA. Exploratory factor analysis was used to examine how adolescents experienced the 12 TAADVA behaviours and through which of the nine ECTs they were experienced. Adolescents' experiences of TAADVA victimisation did not significantly vary in terms of the ECT method used and often multiple TAADVA behaviours were experienced in combination with one another across a range of ECTs, demonstrated by the identification of nine factors in the analysis. The findings highlight implications for understanding and raising awareness of the extent and intrusiveness of TAADVA, particularly when multiple abusive and controlling behaviours are experienced via multiple methods or devices. It is advised that assessing the overall construct of abusive and controlling behaviour is avoided in future research and instead, the multidimensionality of the factors identified in the analysis of the TAADVA assessment tool and the different behaviours that these factors encompass need to be considered.
\end{abstract}

Key words: Adolescent(ce); Technology-Assisted; Dating Violence and Abuse; Electronic Communication Technology 


\section{Technology-Assisted Adolescent Dating Violence and Abuse: A Factor Analysis of the Nature of Electronic Communication Technology Used Across Twelve Types of Abusive and Controlling Behaviour}

\section{Introduction}

Adolescence is defined as the developmental period of 10-18 years old (World Health Organisation 2015), and is a time when young people begin to establish romantic relationships (Connolly, Craig, Goldberg, \& Pepler 2004). Such relationships are important in adolescent social, sexual and identity development (Connolly \& McIsaac 2011; Sorensen 2007). However, dating relationships also place young adolescents at risk of dating violence (Hickman, Jaycox, \& Aronoff 2004).

Adolescent Dating Violence and Abuse (ADVA) has been defined as "physical, sexual, or psychological/emotional violence between two people within a close or dating relationship, as well as stalking. It can occur in person or electronically such as repeated texting or posting sexual pictures of a partner online and may occur between a current or former dating partner" (Centers for Disease Control and Prevention 2012: 1). Notably, this definition captures the role of technology in the instigation of abuse electronically which will be referred to in this paper as Technology-Assisted Adolescent Dating Violence and Abuse (TAADVA). Electronic Communication Technology (ECT) can be used to instigate many types of coercive or controlling behaviour as well as psychological or emotional abuse and threats that have traditionally only been instigated or experienced in person. For example, partners can be isolated via a partner controlling and monitoring of their mobile or online accounts or be prevented from using ECT to contact others (Hinduja \& Patchin 2011; Picard 2007). Additionally, a partner may be embarrassed, humiliated or intimidated publicly via social media or a website (Cutbush, Ashley, Kan, Hampton, \& Hall 2010; Tompson, Benz, \& Agiesta 2013). However, TAADVA is a relatively new phenomenon and very few studies have been conducted exploring its nature and prevalence.

Draucker and Martsolf (2010) found that adolescents use ECT in all stages of their relationships including establishing, maintaining and ending relationships and identified six ways in which technology was used in participants' experiences of teen dating violence: (1) arguing with a partner; (2) monitoring or controlling the activities or whereabouts of a partner; (3) perpetrating emotional or verbal aggression against a partner; (4) seeking help during a violent episode; (5) limiting 
a partner's access to oneself; and (6) reconnecting with a partner after a break-up or violent episode. In their retrospective study of 18-21 year olds' adolescent experiences (at age 13-18) of ADVA and TAADVA, they found that $54 \%$ provided references about the adolescent use of ECT in monitoring or controlling a partner or use of ECT in perpetrating emotional or verbal aggression against a partner. The technology most commonly referenced was the use of a mobile phone, followed by a social networking site (SNS) and then text message. For example, the young adults described how their partner had checked up on them by calling their phone multiple times or checked voice mail recordings or stored text messages to see whom they had been talking to, in addition to being left voice mails or text messages threatening to harm them if they did not return their partner's calls.

A review of 12 TAADVA prevalence studies from the United States (US) and United Kingdom (UK)/Europe with samples aged from 11-24 years old depending on the study found the prevalence for TAADVA victimisation ranged from 12-56\% (Stonard, Bowen, Lawrence, \& Price 2014). Measures used in the studies varied in consistency, the range of behaviours measured and whether the individual ECT used to instigate TAADVA was identified. Only three studies in the review were found to include British adolescents aged 13-17 years depending on the study which each vary in their comprehensiveness (Barter, McCarry, Berridge, \& Evans 2009; Barter et al. 2015; Fox, Corr, Gadd, \& Butler 2014). Barter et al. (2009) found that prevalence rates of TAADVA for females were higher than that for males, specifically for receiving humiliation and threats via mobile phones or the Internet (12\% vs. $4 \%$ ), and being checked up on via a mobile phone or the Internet (42\% vs. 29\%). Fox et al. (2014) only asked one question regarding TAADVA, finding 17\% of adolescents aged 13-14 years had been checked up on to see who they have phoned or sent messages to at least once. Finally, Barter et al. (2015) found that online emotional violence (e.g. putdowns, nasty posts, threats, controlling friends or activities, checking up on a partner and trying to make friends stop liking a partner via a mobile or online) was evident in $40 \%$ of a sample of 14-17 year old adolescents in England and four other EU counties (38-48\% females and 20-46\% males). Little is known about how adolescents experience a range of TAADVA behaviours and through which methods of ECT these are instigated.

Only two studies from the US distinguished between specific methods of ECT through which adolescents experienced and/or instigated TAADVA behaviours (Draucker \& Martsolf 2010; Korchmaros, Ybarra, Langhinrichsen-Rohling, Boyd, \& Lenhart 2013). For example, Draucker and 
Martsolf (2010) examined young people's retrospective experience of TAADVA via phone call, text message, SNS, email, websites and key-loggers, and Korchmaros et al. (2013) looked at instigation experiences offline, online, via phone call and text message. Korchmaros et al. (2013) suggest that mobile phones are particularly relevant to TAADVA due to the almost constant access adolescents have to such communication tools. Zweig, Dank, Yahner, and Lachman (2013) found SNS to be the most frequently reported method used in TAADVA. However, little is known about the nature of British adolescents' experiences of TAADVA behaviours and whether ECT use varies depending on the TAADVA behaviour, which is subsequently explored in this paper and makes an original contribution to knowledge in this field.

In summary, current TAADVA studies have varied in their comprehensiveness and detail leading to inconsistency between studies and raising questions regarding the specific ECT used in TAADVA and the relationship between behaviours experienced. Consequently, this paper aims to explore this issue using a comprehensive TAADVA questionnaire that has been developed to explore 12 types of TAADVA behaviours across a range of ECT methods (call, text, instant messenger, SNS, picture message, video chat, email, chatroom, website/blog). It specifically addresses the research question: What is the nature of ECT used in adolescents' experiences of TAADVA victimisation? It was hypothesised that: The nature of TAADVA behaviours experienced will vary by the ECT method used. For example, it may be that attempts to embarrass and humiliate a partner will be preferred to be done via public methods of ECT (such as SNS), that abusive behaviour consisting of threats or intimidation may be preferred to be instigated via private channels, and that the instigation of sexual pressure or unwanted sexting may be favoured via picture or private text messaging methods of ECT.

\section{Method}

\section{Participants}

A total of 469 adolescents (52\% female; $88 \%$ White British ethnicity) aged between 12-18 years $(M=$ 13.9 years; $S D=1.27$ ) were recruited using opportunity and purposive sampling through schools, youth clubs and via snowballing through contacts of the researcher in Central England. The majority of adolescents reported current or previous romantic relationships $(81 \%)$. The findings reported in this paper are limited to those adolescents $(59 \% ; n=277)$ with past year dating relationship experience and who provided data for the variables used in the subsequent analysis (e.g. $n=274-277$ depending on 
missing data). Of those adolescents with past year dating relationship experience, $57 \%$ were female, all were aged $12-18(M=14.1 ; S D=1.39)$, and $91 \%$ stated their ethnicity as White British.

\section{Procedure}

Once ethical clearance was granted from Coventry University's Research Ethics Committee, the researcher emailed and/or phoned secondary schools and youth clubs to seek gatekeeper approval to recruit participants, in addition to recruiting participants via snowballing methods. Gatekeeper consent was gained from three secondary schools and seven youth clubs. Parents/guardians were informed about the research by letter and consent was obtained using an opt-out procedure before the researcher met the eligible adolescent participants who gave written informed consent. Participants completed a pencil-and-paper questionnaire administered in the same way in each setting using the same introductions, instructions, delivered by the same researcher, with the same process.

\section{Measures}

The TAADVA survey consisted of 12 abusive, threatening, monitoring or controlling TAADVA behaviours (see Table 1) that could be experienced via nine technologies (call, text, instant message, SNS, picture message, video chat, email, chatroom, and website/blog). There were therefore 108 separate items in the TAADVA victimisation survey. This survey was developed by incorporating items from a review of the TAADVA literature and previous measures that have been used in order to create a comprehensive questionnaire that encompassed all possible TAADVA behaviours, and then piloting the survey with adolescents to check the relevance and clarity of the TAADVA behaviours and ECTs identified in this review (Stonard et al. 2014; Stonard, Bowen, Walker, \& Price 2017), before refining the final questionnaire (see supplementary materials). Response options ranged in frequency from (1) ‘never', (2) ‘at least once', (3) ‘monthly’, (4) ‘fortnightly’, (5) ‘weekly’, (6) ‘daily’, to (7) 'hourly' and the timeframe was the last 12 months. The 12 TAADVA victimisation questions (computed for each TAADVA behaviour by the nine ECTs) had Cronbach's alpha scores ranging from $\alpha=.91-.97$, suggesting high internal consistency.

\section{Data analysis}

To address the hypothesis, an exploratory factor analysis was conducted on the 108 TAADVA victimisation items from the questionnaire in order to investigate whether the 12 TAADVA behaviours 
and nine ECTs were related in any way. This allowed the exploration of the relevance of the nine ECTs to adolescents' experience of the 12 TAADVA behaviours. These findings are used to contextualise the nature and significance of the ECT and behaviours through which TAADVA is experienced.

\section{Results}

Almost three-quarters of adolescents (73\%) reported experience of some form of TAADVA at least once in the past 12 months. The prevalence of the individual TAADVA behaviours measured varied from $12 \%$ (e.g. prevention of technology use) to $56 \%$ (e.g. checking up on a partner to see where they are, who they are with etc.). These findings are reported in more detail elsewhere (Stonard 2018). The descriptive statistics of the raw data from the 12 TAADVA behaviours by each of the nine ECTs is provided in the supplementary materials. As there were some clear patterns in the descriptive frequencies of the nine types of ECTs, a brief summary of these findings from the raw data is provided for context before presenting the findings from the exploratory factor analysis.

\section{Summary of the raw TAADVA victimisation prevalence data}

It was expected that the use of phone calls, text messages and SNS would be particularly relevant to TAADVA given the previous literature (Korchmaros et al. 2013; Draucker \& Martsolf 2010; Zweig et al. 2013). This appeared to be true for text messaging and SNS. There was a trend across 9/12 TAADVA behaviours for text messaging to be the most prevalent form of ECT used in these experiences of victimisation (Table 2). The three behaviours for which this was an exception were for being threatened (the most common method was via phone call), embarrassed and humiliated, and receiving unwanted sexting (in which the most common method was via a SNS), although for the latter two behaviours this difference was marginal.

The next most prevalently used ECT method was SNS, with 6/12 TAADVA behaviours being the next most commonly reported experience via this method (Table 2). For the other six behaviours measured (e.g. embarrassment/humiliation, threats, checking up on a partner's whereabouts, sexting pressure, unwanted sexting, feeling afraid to not respond to communication), the next most commonly used ECT was text message or phone call. The third most prevalent ECT used across the TAADVA behaviours was instant messenger and this was the case for 7/12 behaviours (Table 2). For the five behaviours that did not follow this trend, the next most prevalent ECTs used were SNS (for threats and 
sexting pressure), phone call (for demanding passwords and deleting contacts) and picture message (for unwanted sexting). There was a clear trend for email, chatroom and website/blog methods to consistently be the least prevalent forms of ECT through which adolescents' experienced TAADVA victimisation and with marginal differences in the prevalence of the use of such ECTs.

\section{Exploratory Factor Analysis of the TAADVA victimisation items}

An exploratory factor analysis of the 108 TAADVA victimisation questions with oblimin rotation was conducted to explore whether the 12 TAADVA behaviours and nine ECTs were related or experienced as unique distinct behaviours and/or ECTs in isolation from one another. Non-orthogonal rotation was used due to there being good theoretical reason to suppose that the factors could be related (Field 2009). The Kaiser-Meyer-Olkin (KMO) measure verified the sampling adequacy for the analysis, $\mathrm{KMO}=.83$ (Kaiser 1974, cited in Field 2009: 647). An initial analysis was run to obtain eigenvalues for each factor in the data. Scree plots were used to determine the number of factors to extract and the main breakpoint occurred just prior to the ninth, so nine factors were extracted. These nine factors had eigenvalues over Kaiser's criterion $<1$ and in combination explained $73.9 \%$ of the variance. Factor loadings above .3 were used to interpret the factor structure (Field 2009). The pattern matrix factor loadings and factor correlation matrix are provided in Tables 4-5 and a summary of these nine factors is provided in Table 3.

The overarching latent trait is defined as 'Abusive Behaviours' (Table 3). The nine factors are labelled based on the behaviour(s) included as follows: (1) controlling manipulation; (2) exploitation; (3) monitoring communication; (4) isolation; (5) intimidation; (6) coercive pressure; (7) identity devaluation; (8) monitoring whereabouts; and (9) emotional abuse (Table 3).

The nine unique factors were identified based on behaviour type. It was clear that the type of ECT used was not relevant to this underlying structure, meaning that the hypothesis was rejected, as the TAADVA behaviours experienced did not cluster by ECT method. It was expected that some ECTs may relate to specific TAADVA behaviours (e.g. unwanted sexting via picture messages and embarrassment via public SNS), however this was not the case in these findings. Table 3 (also see Table 4) shows that when adolescents experience TAADVA they often experience multiple behaviours through a number of ECT methods. Factor three (monitoring communication) and eight (monitoring whereabouts) are unique factors, characterised by all possible methods of ECT for these monitoring 
communication and whereabouts behaviours. Factor nine (emotional abuse) is also loaded as a unique behaviour (insults) on four of the ECTs. The three uniquely loaded behaviours may be perceived as milder in severity in their nature and if experienced alone, or potentially more common in adolescent dating relationships.

Some logical interpretations can be made in an attempt to understand why several types of behaviours would cluster together on the six factors for which this was identified. Factors one (controlling manipulation) and four (isolation) appear to represent a combination of fairly serious behaviours such as demanding passwords, sexting pressure, unwanted sexting and one threat item (Factor 1); and deleting contacts, prevention of ECT use to talk to others and embarrassment/humiliation (Factor 4). These findings may suggest that one type of TAADVA behaviour is possibility connected to or experienced alongside another behaviour. For example, deleting a partner's contacts may be used to prevent a partner from using ECTs to talk to others. The second factor (exploitation) comprised of all nine ECT methods regarding the sharing/distributing of information or images, in addition to insults via five ECTs. These behaviours may be related as namecalling could be used in conjunction with attempts to hurt a partner in other ways (i.e. sharing their private information). The fifth factor (intimidation) included all the nine ECT items for feeling afraid to not respond to a partner, in addition to three of the ECT items for unwanted sexting and one ECT item for being embarrassed/humiliated. These three behaviours may also relate to each other, for example, receiving unwanted sexting may lead to the recipient feeling afraid not to respond to such messages, or to send sexting messages themselves. The sexting pressure and unwanted sexting items were also loaded on factor six (coercive pressure), in addition to prevention of ECT use. The seventh factor (identity devaluation) encompassed eight of the nine ECTs for threatening behaviour in addition to six of the embarrassment/humiliation items. Notably, the two sexting TAADVA behaviours (sexting pressure and receiving unwanted sexts) were loaded across three different factors, accompanied by controlling, threatening and humiliating behaviours indicating that sexual TAADVA was not experienced in isolation from non-sexual forms of TAADVA. These findings offer new insights into the complex nature of adolescents' experiences of 12 TAADVA behaviours and the range of ECTs through which these are experienced in addition to behaviours that are experienced exclusively. 


\section{Discussion}

This paper explored the nature of TAADVA experienced by adolescents aged 12-18 years in terms of the types of behaviours and ECT methods used. Little research has been previously done to explore TAADVA and this study presents a unique contribution by examining the relationship between different methods of ECT and various TAADVA behaviours that can be experienced via such tools using factor analysis.

It was anticipated that the ECT through which adolescents experience or use TAADVA may vary depending on the behaviour, however this was not the case, meaning the hypothesis was rejected. The TAADVA behaviours were often not experienced in isolation from one another. These findings offer unique insights into the nature of TAADVA victimisation experiences encompassing 12 different TAADVA behaviours and nine possible ECT methods. Notably, the sexting pressure and unwanted sexting items were also loaded with other abusive and controlling behaviours in three factors (factor 1: controlling manipulation; factor 5: intimidation; and factor 6: coercive pressure). This may have implications for the impact of such behaviours especially as evidence has been found to support the notion that sexual ADVA and TAADVA is gendered, being characterised by female victimisation and male instigation (Barter et al. 2009; Foshee 1996; Zweig et al. 2013).

When sexual abuse is experienced as a continuum of abusive behaviour along side other emotionally abusive and controlling behaviours, this may result in unique experiences and impacts for female victims compared to male victims. For example, young females may feel that pressure to send and receive sexing images and to engage in sexual relationships is a normal part of relationship exploration as a result of socio-cultural gender role expectations. This has been highlighted by Ringrose, Gill, Livingstone, and Harvey (2012) who suggest that females learn gendered and sexualised expectations of behaviours in romantic and sexual relationships. A key finding in Ringrose et al.'s (2012) study was that males used threats and the sharing of images not only to expose, humiliate or spread rumours about a female partner, but also with the intent to get 'ratings' from peers. These 'ratings' are reported to be reinforced by normalised sexism at the peer and cultural level, which contributes to the sexual double standards that are represented by the harassment of girls and requests for sexual acts and/or images and the subsequent judgement of them as 'sluts' for engaging in such behaviour (Ringrose et al. 2012; Ringrose, Harvey, Gill, \& Livingstone 2013). Such norms appear to 
legitimise the pressure to send and the sharing of sexting images, which may be used as a form of bullying or dating violence resulting in impacts that are not gender-neutral.

Moreover, the ECT through which TAADVA is experienced was not particularly relevant and behaviours were often experienced via a range of methods. This may be an artefact of the availability of multiple methods of ECT (i.e. calling, texting, emailing, sending picture messages and video chat), and applications for such uses, in addition to the availability of the Internet on multiple platforms (e.g. a mobile or smartphone, a tablet, or laptop computer). While Draucker and Martsolf (2010) and Korchmaros et al. (2013) found mobile phones to be the most frequently reported ECT used in TAADVA, this paper found text messaging followed by SNS and then instant messenger to be the most prevalent. Zweig et al. (2013) also found SNS to be the most commonly used ECT in TAADVA. Email, chatroom and websites/blogs were least prevalent. Texts and mobile phone calls are accessible methods of ECT to adolescents; however, increasingly young people have access to the Internet via smart phones and tablets that enable the use of SNS more easily as a result of availability (Ofcom 2015). It is possible that the different ECTs that adolescents use in TAADVA will change over time in terms of preference and along with the development of ECT. As ECT continues to develop more research will be needed to catch up and update our understanding of how ECTs used in TAADVA. No other study has explored the relationship between the ECTs used and types of TAADVA behaviours to compare these findings to. These findings highlight a need to consider the role of ECT methods in TAADVA in future questionnaires and in research regarding the impact of experiencing TAADVA via different methods (i.e. private and public).

The finding that being checked up on by a partner, having messages checked by a partner, and receiving insults by ECT were uniquely loaded in the factor structure may lend support to the idea that these behaviours are potentially more common and normalised in adolescent romantic relationships. Prevalence studies have identified that $27-42 \%$ of adolescents report being checked up on by a partner or having their messages checked (Associated Press and MTV 2011; Barter et al. 2009) and 25-36\% have received insults or hurtful comments from a partner via ECT (Cutbush et al. 2010; Picard 2007). Indeed, adolescents have been found to view checking a partner's phone and messages to be as perceived to be common behaviours among young people's social networks (Stonard et al. 2017). Additionally, such behaviours could be potentially perceived as less severe if experienced in isolation (rather than a range of abusive and controlling behaviours). For example, some adolescents do not 
perceive monitoring a partner's messages as particularly harmful (Baker \& Carreño 2016; Lucero, Weisz, Smith-Darden, \& Lucero 2014). Research has also found that some adolescents view TAADVA behaviours as problematic only when they occurred outside of dating relationships (Lucero et al. 2014). Draucker and Martsolf (2010) found eight ways in which ECT was used in dating relationships for both non-abusive and abusive purposes. It is therefore likely that for some adolescents, some TAADVA behaviours such as monitoring or controlling a partner and emotional abuse are normalised in adolescent romantic relationships.

It must be noted that data was collected with self-report surveys meaning it is subject to response bias, potential variations in how participants interpret terms, problems of memory recall (Bryman 2004). The findings may not be generalisable to the wider population nationally due to an opportunity sample being used. In addition, in some cases up to three participants did not complete all questions regarding TAADVA victimisation in the survey. Nevertheless, no other research has investigated the structural nature of TAADVA using factor analysis meaning this study offers a unique and original contribution to our understanding of the nature of TAADVA victimisation in terms of the behaviours and ECT methods used. Furthermore, the findings of this paper raise several important suggestions for improving theory, practice and future research.

It is clear that TAADVA is evident in a significant proportion of adolescent romantic relationships. This needs acknowledging in future theorisation of ADVA that recognises the role of ECT and potentially new forms of abusive behaviour (e.g. pressured sexting, and public humiliation online via social media). TAADVA may also have unique impacts for victims as ECT allows those who wish to instigate TAADVA to do it easily, with great accessibility and through a diverse range of methods while reaching a potentially wide public audience (Bryant, Sanders-Jackson, \& Smallwood 2006). Traditional theories that have been used to explain ADVA such as social learning, attachment, feminist theories are likely to also be relevant in explaining TAADVA (Wekerle \& Wolf 1999), however these theories may need adapting and new contemporary theories applied in order to explain the facilitators and impact of TAADVA fully (e.g. the accessibility, anonymity, and intrusive nature of TAADVA instigated via ECT).

The findings highlight the importance of acknowledging TAADVA as well as ADVA in definitions, policy, and prevention strategies. Furthermore, the findings emphasise the importance of recognising that the platform of ECT used seems to matter less than the nature of the type of TAADVA 
experienced as TAADVA behaviours appear to be experienced across a range of ECT methods. The unique nature of TAADVA and the diverse range of ECTs through which a range of TAADVA behaviours are experienced should be recognised in terms of their individual and collective impact if experienced together alongside other abusive and potentially coercive and controlling behaviours and in terms of recognising the pervasive and potentially intrusive nature of experiencing TAADVA via a range of ECT methods. This will help to inform future theoretical explanations of TAADVA in addition to informing prevention and intervention efforts. The new concepts (factors) identified in the analysis could also be applied to theoretical explanations of TAADVA, for example, in developing and adapting a TAADVA power and control wheel as originally created by Pence and Paymar (1993) for offline partner violence among adults. These factors my also be used in training for practitioners working with victims as well as adolescents in terms of preventative education. The findings highlight a need for preventative education regarding ECT use and healthy relationships including TAADVA as well as ADVA and how to safely report abuse and/or block unwanted or abusive contact.

The findings also highlight several suggestions for future research. Future research can validate the TAADVA survey used and the factors identified in the findings reported on in this study that can be used as potential subscales. Future research should also explore the impact of TAADVA and what role specific types of ECTs play (e.g. private text message or public SNS or website/blog) in the meaning and impact of TAADVA for both victims and instigators and whether this differs across the sexes. For example, future questionnaires can examine the impact of the various TAADVA behaviours or factors based on the ECT method used or the combination of ECT methods used (e.g. humiliation via social media may be more hurtful and impactful than if done via a personal text message). In addition, exploring the impact and potential outcomes (e.g. self-esteem, self-efficacy, internalising symptoms, substance use, offline violence, or other emotional effects) of the items that encompass the different factors identified and whether there are gender differences in these outcomes would prove insightful. Another suggestion for future research is the exploration of the extent to which adolescents view some TAADVA behaviours and the use of ECTs in this context as a normal part of romantic relationships and the impact that this has on their relationship expectations, relationship closeness and relationship satisfaction. Importantly, it is advised that assessing the overall construct of abusive and controlling behaviour is avoided in future research and instead, the multidimensionality of 
the factors identified in the analysis of the TAADVA assessment tool and the different behaviours that these factors encompass need to be considered.

\section{Compliance with ethical standards}

\section{Disclosure of potential conflicts of interest: None}

Research involving Human Participants and/or Animals: All procedures performed in studies involving human participants were in accordance with the ethical standards of the institutional and/or national research committee and with the 1964 Helsinki declaration and its later amendments or comparable ethical standards. Ethical clearance was granted from Coventry University's Research Ethics Committee and these standards and guidelines were also followed.

Informed consent: Informed consent was obtained from all individual participants included in the study.

\section{Author Contributions}

KES designed and executed the study, conducted the data analyses, and wrote the paper.

\section{References}

Associated Press \& MTV. (2011). Associated Press-MTV Digital Abuse Survey August 2011. Retrieved from http://www.athinline.org/pdfs/2011-MTV-AP_Digital_Abuse_Study_Full.pdf

Baker, C. K., \& Carreño, P. K. (2016). Understanding the Role of Technology in Adolescent Dating and Dating Violence. Journal of Child and Family Studies, 25, 308-320. Doi: 10.1007/s10826-0150196-5

Barter, C., McCarry, M., Berridge, D., \& Evans, K. (2009). Partner Exploitation and Violence in Teenage Intimate Relationships. London: NSPCC

Barter, C., Wood, M., Aghtaie, N., Larkins, C., Stanley, N., Apostolov, G., et al. (2015). Briefing Paper 2: Incidence Rates and Impact of Experiencing Interpersonal Violence and Abuse in Young People’s Relationships. Safeguarding Teenage Intimate Relationships: Connecting Online and Offline Contexts and Risks. Funded by DAPHNE III European Commission. Retrieved from http://stiritup.eu/wp-content/uploads/2015/02/STIR-Briefing-Paper-21.pdf 
Bryant, J. A., Sanders-Jackson, A., \& Smallwood, A. M. K. (2006). IMing, Text Messaging, and Adolescent Social Networks. Journal of Computer-Mediated Communication, 11, 577-592. Doi: 10.1111/j.1083-6101.2006.00028.x

Bryman, A. (2004). Social Research Methods. 2nd edn. Oxford: Oxford University Press

Centers for Disease Control and Prevention. (2012). Understanding Teen Dating Violence. Retrieved from http://www.cdc.gov/violenceprevention/pdf/teen-dating-violence-factsheet-a.pdf

Connolly, J., Craig, W., Goldberg, A., \& Pepler, D. (2004). Mixed-Gender Groups, Dating, and Romantic Relationships in Early Adolescence. Journal of Research on Adolescence, 14, 185-207. Doi: 10.1111/j.1532-7795.2004.01402003.x

Connolly, J., \& McIsaac, C. (2011). Romantic Relationships in Adolescence. In K. M. Underwood and L. H. Rosen (Eds.), Social Development: Relationships in Infancy, Childhood and Adolescence (pp. 180-20). New York: The Guilford Press

Cutbush, S., Ashley, O. S., Kan., M. L., Hampton, J., \& Hall, D. M. (2010). Electronic Aggression Among Adolescent Dating Partners: Demographic Correlates and Associations with Other Types of Violence. Poster presented at the American Public Health Association annual meeting, November 6-10. Denver, CO. Retrieved from http://www.rti.org/pubs/apha10_cutbush_poster.pdf

Draucker, C. B. \& Martsolf, D. S. (2010). The Role of Electronic Communication Technology in Adolescent Dating Violence. Journal of Child and Adolescent Psychiatric Nursing, 23, 133-142. Doi: $10.1111 / \mathrm{j} .1744-6171.2010 .00235 . \mathrm{x}$

Field, A. (2009). Discovering Statistics Using SPSS. 3rd edn. London: SAGE

Foshee, V. A. (1996). Gender Differences in Adolescent Dating Abuse Prevalence, Types and Injuries. Health Education Research, 11, 275-286. Doi: 10.1093/her/11.3.275-a

Fox , C. L., Corr, M. L., Gadd, D., \& Butler, I. (2014). Young Teenagers' Experiences of Domestic Abuse. Journal of Youth Studies, 17, 510-526. Doi: 10.1080/13676261.2013.780125

Hickman, L. J., Jaycox, L. H., \& Aronoff, J. (2004). Dating Violence Among Adolescents: Prevalence, Gender Distribution, and Prevention Program Effectiveness. Trauma, Violence and Abuse, 5, 123142. Doi: $10.1177 / 1524838003262332$

Hinduja, S., \& Patchin, J. W. (2011). Electronic Dating Violence: A Brief Guide for Educators and Parents. Cyberbullying Research Center. Retrieved from http://www.cyberbullying.us/electronic_dating_violence_fact_sheet.pdf 
Kaiser, H. F. (1974). An index of factorial simplicity. Psychometrika, 39, 31-36

Korchmaros, J. D., Ybarra, M. L., Langhinrichsen-Rohling, J., Boyd, D. and Lenhart, A. (2013). Perpetration of Teen Dating Violence in a Networked Society. Cyberpsychology, Behavior, and Social Networking, 16, 561-567

Lucero, J. L., Weisz, A. N., Smith-Darden, J., \& Lucero, S. M. (2014). Exploring Gender Differences: Socially Interactive Technology Use/Abuse Among Dating Teens. Affilia, 29, 478-491. Doi: $10.1177 / 0886109914522627$

Ofcom. (2015). The Communications Market Report. Retrieved from https://www.ofcom.org.uk/_data/assets/pdf_file/0022/20668/cmr_uk_2015.pdf

Pence, E., \& Paymar, M. (1993). Education Groups for Men who Batter: The Duluth Model. New York: Springer

Picard, P. (2007). Tech Abuse in Teen Relationships. Chicago, IL: Teen Research Unlimited Ringrose, J., Harvey, L., Gill, R., \& Livingstone, S. (2013). Teen Girls, Sexual Double Standards and 'Sexting’: Gendered Value in Digital Image Exchange. Feminist Theory, 14, 305-323

Ringrose, J., Gill, R., Livingstone, S., \& Harvey, L. (2012). A Qualitative Study of Children, Young People and 'Sexting': A Report Prepared for the NSPCC. London: NSPCC.

Sorensen, S. (2007). Adolescent Romantic Relationships. ACT for Youth Centre of Excellence. Retrieved from http://www.actforyouth.net/resources/rf/rf_romantic_0707.pdf

Stonard, K. E. (2018). The Prevalence and Overlap of Technology-Assisted and Offline Adolescent Dating Violence. Submitted manuscript accepted for publication in Current Psychology subject to minor revisions

Stonard, K. E., Bowen, E., Lawrence, T. R., \& Price, S. A. (2014). The Relevance of Technology to the Nature, Prevalence and Impact of Adolescent Dating Violence and Abuse: A Research Synthesis. Aggression and Violent Behavior, 19, 390-417. Doi: 10.1016/j.avb.2014.06.005

Stonard, K., Bowen, E., Walker, K., \& Price, S. A. (2017). “They’ll Always Find a Way to Get to You”: Technology Use in Adolescent Romantic Relationships and Its Role in Dating Violence and Abuse. Journal of Interpersonal Violence, 32, 2083-2117. Doi: 10.1177/0886260515590787

Tompson, T., Benz, J., \& Agiesta, J. (2013). The Digital Abuse Study: Experiences of Teens and Young Adults. AP-NORC Centre for Public Affairs Research. Retrieved from 
http://www.apnorc.org/PDFs/Digital\%20Abuse/AP-

NORC\%20Center\%20and\%20MTV_Digital\%20Abuse\%20Study_FINAL.pdf

Wekerle, C., \& Wolfe, D. A. (1999). Dating Violence in Mid-Adolescence: Theory, Significance, and Emerging Prevention Initiatives. Clinical Psychology Review, 19, 435-456. Doi: 10.1016/S02727358(98)00091-9

World Health Organization. (2015). Adolescent Development. Retrieved from http://www.who.int/maternal_child_adolescent/topics/adolescence/dev/en/

Zweig, J. M., Dank, M., Yahner, J., \& Lachman, P. (2013). The Rate of Cyber Dating Abuse Among Teens and How it Relates to Other Forms of Teen Dating Violence. Journal of Youth and Adolescence, 42, 1063-1077. Doi: 10.1007/s10964-013-9922-8 
Tables

Table 1

TAADVA behaviour items

\begin{tabular}{ll}
\hline No. & TAADVA behaviour items \\
\hline 1 & Insulting, mean or hurtful comments \\
3 & Shbarrassing or humiliating a partner \\
4 & Threatening a partner \\
5 & Checking up on a partners whereabouts \\
6 & Pressure to engage in unwanted sexting \\
7 & Receiving unwanted sexting \\
8 & Checking messages, contact histories or friend lists \\
9 & Demanding a partner's passwords \\
10 & Deleting friends or contacts from a partner's mobile or online accounts \\
11 & Feel afraid to not respond to communication from a partner \\
12 & Prevention of ECT use to talk to others
\end{tabular}




\section{Table 2}

The most prevalent ECTs used in TAADVA behaviours

\begin{tabular}{|c|c|}
\hline Most prevalent ECTs used & Behaviours for which this ECT was most commonly used \\
\hline \multirow[t]{9}{*}{ 1. Text message } & 1. Insults \\
\hline & 2. Information shared or distributed \\
\hline & 3. Having whereabouts checked up on \\
\hline & 4. Sexting/sexual pressure \\
\hline & 5. Having messages checked \\
\hline & 6. Having passwords demanded \\
\hline & 7. Deleting contacts \\
\hline & 8. Feeling afraid to not respond to communication \\
\hline & 9. Prevention of ECT use \\
\hline \multirow[t]{6}{*}{ 2. Social Networking Sites } & 1. Insults \\
\hline & 2. Information shared or distributed \\
\hline & 3. Checking messages, contact histories, friend lists \\
\hline & 4. Having passwords demanded \\
\hline & 5. Having contacts deleting \\
\hline & 6. Prevention of ECT use \\
\hline \multirow[t]{7}{*}{ 3. Instant Messenger } & 1. Insults \\
\hline & 2. Embarrassment or humiliation \\
\hline & 3. Information shared or distributed \\
\hline & 4. Having whereabouts checked up on \\
\hline & 5. Checking messages, contact histories, friend lists \\
\hline & 6. Feeling afraid to not respond to communication \\
\hline & 7. Prevention of ECT use \\
\hline
\end{tabular}


Table 3

Factor loadings for the TAADVA victimisation questions: 'Abusive Behaviours'

\begin{tabular}{|c|c|c|c|c|}
\hline Factor & Definition & Behaviour(s) & $n^{\mathbf{a}}$ & ECTs $^{b}$ \\
\hline \multirow[t]{4}{*}{1} & Controlling & Demand password & 9 & PC; TM; IM; SNS; PM; VC; EM; CR; WB \\
\hline & manipulation & Unwanted sexting & 4 & WB; CR; EM; VC \\
\hline & & Sexual/sexting pressure & 3 & CR; EM; WB \\
\hline & & Threat & 1 & EM \\
\hline \multirow[t]{2}{*}{2} & Exploitation & Shared/distributed info & 9 & PC; TM; IM; SNS; PM; VC; EM; CR; WB \\
\hline & & Insults & 5 & CR; WB; EM; PM; VC \\
\hline 3 & Monitoring & Checked messages & 9 & PC; TM; IM; SNS; PM; VC; EM; CR; WB \\
\hline & communication & & & \\
\hline \multirow[t]{3}{*}{4} & Isolation & Deleted friends & 9 & PC; TM; IM; SNS; PM; VC; EM; CR; WB \\
\hline & & Prevention of ECT use & 4 & EM; CR; WB; VC \\
\hline & & Embarrass/humiliate & 2 & EM; WB \\
\hline \multirow[t]{3}{*}{5} & Intimidation & Afraid not respond & 9 & PC; TM; IM; SNS; PM; VC; EM; CR; WB \\
\hline & & Unwanted sexting & 3 & PC; SNS; IM \\
\hline & & Embarrass/humiliate & 1 & $\mathrm{CR}$ \\
\hline \multirow[t]{3}{*}{6} & Coercive & Sexual/sexting pressure & 6 & TM; PM; SNS; VC; IM; PC \\
\hline & Pressure & Unwanted sexting & 2 & PM; TM \\
\hline & & Prevention of ECT use & 5 & PM; TM; IM; SNS; PC \\
\hline \multirow[t]{2}{*}{7} & Identity & Threats & 8 & SNS; IM; TM; PC; PM; CR; VC; WB \\
\hline & devaluation & Embarrass/humiliate & 6 & IM; TM; SNS; PC; PM; VC \\
\hline 8 & Monitoring & Contact to check up on & 9 & PC; TM; IM; SNS; PM; VC; EM; CR; WB \\
\hline
\end{tabular}


whereabouts

9 Emotional abuse Insults $4 \quad$ TM; IM; SNS; PC

Note: ${ }^{a}$ Number of ECT items; ${ }^{b}$ ECTs: PC: Phone Call; TM: Text Message; IM: Instant Messenger;

SNS: Social Networking Site; PM: picture Message; VC: Video Chat; EM: Email; CR: Chatroom; WB:

Website/Blog 
Table 4

Pattern matrix summary of the exploratory factor analysis for the TAADVA victimisation measure $(n=274-277)$

Overarching Latent Trait: Abusive Behaviours

Factor loadings

Item

1. Unwanted sexting - WB

2. Unwanted sexting - CR

3. Demanded passwords - EM

4. Demanded passwords - PM

5. Demanded passwords - WB

6. Demanded passwords - CR

7. Demanded passwords - SNS

8. Demanded passwords - PC

9. Unwanted sexting - EM

10. Demanded passwords - VC

11. Sexting pressure - CR

12. Sexting pressure $-\mathrm{EM}$

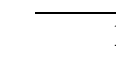

.647

.642

.622

.616

.614

$-.303$

.580

.551

.532

.510

.499

.467

.303

.451
.315

.340 
13. Unwanted sexting - VC $\quad \mathbf{. 4 2 7}$

15. Demanded passwords - IM

16. Threats - EM

18. Shared/distributed information - WB

19. Shared/distributed information - VC

$-.033$

.718

20. Shared/distributed information - EM

21. Shared/distributed information - CR

22. Shared/distributed information - PM

23. Shared/distributed information - IM

24. Shared/distributed information - SNS

27. Insults - WB

28. Insults - EM 


$\begin{array}{llll}\text { 31. Insults - VC } & .077 & \mathbf{. 3 8 6} & \\ \text { 32. Checked messages - PC } & -.091 & \mathbf{. 9 2 5} & \mathbf{- 9 1 4} \\ \text { 33. Checked messages - IM } & -.093 & \mathbf{. 8 7 8} \\ \text { 34. Checked messages - SNS } & -.126 & \mathbf{- . 8 7 5} \\ \text { 35. Checked messages - PM } & -.055 & \mathbf{. . 8 7 4} \\ \text { 36. Checked messages - TM } & -.109 & \mathbf{- . 8 2 9} \\ \text { 37. Checked messages - VC } & .093 & \mathbf{. . 7 9 6} & \\ \text { 38. Checked messages - EM } & .178 & \mathbf{- . 7 6 0} & \\ \text { 39. Checked messages - CR } & .242 & \mathbf{- . 7 5 3} & \\ \text { 40. Checked messages - WB } & .237 & & \mathbf{. 9 0 5} \\ \text { 41. Deleted contacts - VC } & .042 & & \mathbf{. 9 0 3} \\ \text { 42. Deleted contacts - CR } & .032 & & \mathbf{. 8 9 0} \\ \text { 43. Deleted contacts - EM } & .030 & & \mathbf{. 8 9 0} \\ \text { 44. Deleted contacts - WB } & .054 & & \mathbf{. 8 6 0} \\ \text { 45. Deleted contacts - PM } & -.040 & & \mathbf{. 8 5 6} \\ \text { 46. Deleted contacts - PC } & -.081 & \mathbf{. 8 5 6} \\ \text { 47. Deleted contacts - TM } & -.074 & & \\ \text { 48. Deleted contacts - IM } & -.066 & & \end{array}$


51. Prevention of ECT use - CR

52. Prevention of ECT use - WB

54. Embarrassed/humiliated - EM

.429

.412

55. Embarrassed/humiliated - WB

.353

56. Afraid to not respond - PM

57. Afraid to not respond - IM

60. Afraid to not respond-CR

61. Afraid to not respond-EM

63. Afraid to not respond- PC 
67. Embarrassed/humiliated - CR

68. Unwanted sexting - IM

69. Sexting pressure $-\mathrm{TM}$

70. Sexting pressure $-\mathrm{PM}$

71. Sexting pressure - SNS

72. Unwanted sexting - PC

73. Prevention of ECT use - PM

75. Sexting pressure $-\mathrm{VC}$

76. Sexting pressure - IM

78. Unwanted sexting - TM

79. Prevention of ECT use - SNS

81. Prevention of ECT use - PC

82. Threats - SNS 
87. Threats - TM

88. Threats - PC

90. Embarrassed/humiliated - PC

91. Threats $-\mathrm{CR}$

93. Embarrassed/humiliated - PM

94. Embarrassed/humiliated - VC

96. Check up on / whereabouts - PM

97. Check up on / whereabouts - VC

99. Check up on / whereabouts - IM

100. Check up on / whereabouts - TM 
103. Check up on / whereabouts - EM

104. Check up on / whereabouts - WB

105. Insults - TM

106. Insults - IM

107. Insults - SNS

108. Insults - PC
.248

.248

.110

.020

$-.065$

.017
.608

.598

.661

.597

.575

.571

$\begin{array}{cccccccccc}\text { Eigenvalues } & 42.62 & 7.83 & 6.77 & 5.55 & 4.87 & 4.06 & 3.25 & 2.58 & 2.23 \\ \text { \% of variance } & 39.47 & 7.25 & 6.27 & 5.14 & 4.51 & 3.76 & 3.01 & 2.39 & 2.07\end{array}$

Note: Bold entries represent items loaded on each factor. Factor labels: (1) controlling manipulation; (2) exploitation; (3) monitoring communication; (4) isolation; (5)

intimidation; (6) coercive pressure; (7) identity devaluation; (8) monitoring whereabouts; and (9) emotional abuse 
Table 5

Factor Correlation Matrix

\begin{tabular}{ccccccccccc}
\hline Factor & $\mathbf{1}$ & $\mathbf{2}$ & $\mathbf{3}$ & $\mathbf{4}$ & $\mathbf{5}$ & $\mathbf{6}$ & $\mathbf{7}$ & $\mathbf{8}$ & $\mathbf{9}$ \\
\hline $\mathbf{1}$ & 1.000 & .192 & -.269 & .197 & .221 & .211 & -.173 & .152 & -.124 \\
$\mathbf{2}$ & - & 1.000 & -.306 & .221 & .151 & .219 & -.402 & .332 & .097 \\
$\mathbf{3}$ & - & - & 1.000 & -.349 & -.281 & -.314 & .231 & -.381 & -.083 \\
$\mathbf{4}$ & - & - & - & 1.000 & .337 & .300 & -.368 & .246 & -.028 \\
$\mathbf{5}$ & - & - & - & - & 1.000 & .332 & -.309 & .258 & .095 \\
$\mathbf{6}$ & - & - & - & - & - & 1.000 & -.267 & .136 & -.016 \\
$\mathbf{7}$ & - & - & - & - & - & - & 1.000 & -.255 & -.163 \\
$\mathbf{8}$ & - & - & - & - & - & - & - & 1.000 & .153 \\
$\mathbf{9}$ & - & - & - & - & - & - & - & - & 1.000 \\
\hline
\end{tabular}




\section{Supplementary Materials}

TAADVA Victimisation Questionnaire

\section{Technology-Assisted Dating Abuse Received}

Please use the following KEY to rate for each technology media, how often you have RECEIVED the following behaviours from your current or a recent girlfriend or boyfriend in the LAST 12 MONTHS. Please answer as accurately and honestly as possible.

KEY

\begin{tabular}{|ccccccc|}
\hline $\mathbf{1}$ & $\mathbf{2}$ & $\mathbf{3}$ & $\mathbf{4}$ & $\mathbf{5}$ & $\mathbf{6}$ & $\mathbf{7}$ \\
\hline Never & $\begin{array}{c}\text { At least } \\
\text { once }\end{array}$ & Monthly & $\begin{array}{c}\text { Fort- } \\
\text { nightly }\end{array}$ & Weekly & Daily & Hourly \\
\hline
\end{tabular}

Insulting, mean or hurtful personal comments e.g. called you names, put downs etc.

\begin{tabular}{|c|c|c|c|c|c|c|c|}
\hline Phone Call & 1 & 2 & 3 & 4 & 5 & 6 & 7 \\
\hline Text Message & 1 & 2 & 3 & 4 & 5 & 6 & 7 \\
\hline Instant Messenger & 1 & 2 & 3 & 4 & 5 & 6 & 7 \\
\hline Social Networking Site & 1 & 2 & 3 & 4 & 5 & 6 & 7 \\
\hline Picture Message & 1 & 2 & 3 & 4 & 5 & 6 & 7 \\
\hline Video Chat & 1 & 2 & 3 & 4 & 5 & 6 & 7 \\
\hline Email & 1 & 2 & 3 & 4 & 5 & 6 & 7 \\
\hline Chatroom & 1 & 2 & 3 & 4 & 5 & 6 & 7 \\
\hline Website/Blog & 1 & 2 & 3 & 4 & 5 & 6 & 7 \\
\hline \multirow[b]{2}{*}{ KEY } & 1 & 2 & 3 & 4 & 5 & 6 & 7 \\
\hline & Never & $\begin{array}{c}\text { At least } \\
\text { once }\end{array}$ & Monthly & $\begin{array}{c}\text { Fort- } \\
\text { nightly }\end{array}$ & Weekly & Daily & Hourly \\
\hline
\end{tabular}

Comments or acts that were intended to embarrass, humiliate or shame you e.g. spreading rumours

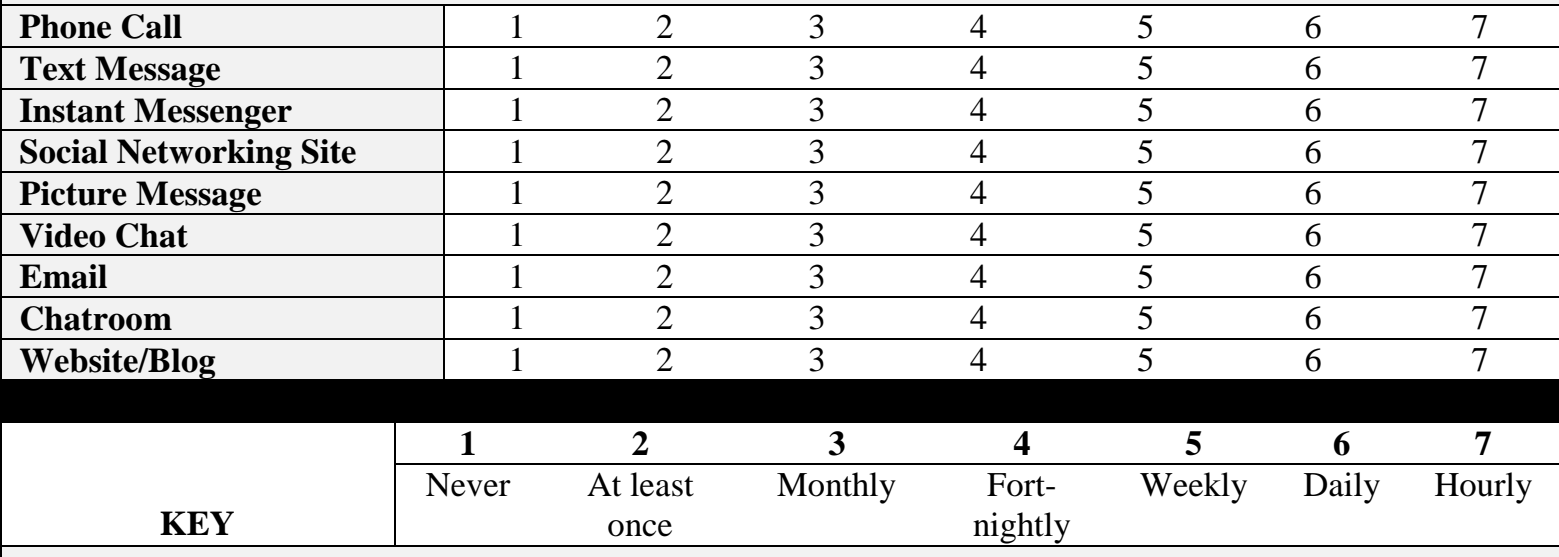

Shared or distributed private or personal information/images/video etc..

\begin{tabular}{|l|llllllll|}
\hline Phone Call & 1 & 2 & 3 & 4 & 5 & 6 & 7 \\
\hline Text Message & 1 & 2 & 3 & 4 & 5 & 6 & 7 \\
\hline Instant Messenger & 1 & 2 & 3 & 4 & 5 & 6 & 7 \\
\hline Social Networking Site & 1 & 2 & 3 & 4 & 5 & 6 & 7 \\
\hline Picture Message & 1 & 2 & 3 & 4 & 5 & 6 & 7 \\
\hline Video Chat & 1 & 2 & 3 & 4 & 5 & 6 & 7 \\
\hline Email & 1 & 2 & 3 & 4 & 5 & 6 & 7 \\
\hline Chatroom & 1 & 2 & 3 & 4 & 5 & 6 & 7 \\
\hline Website/Blog & 1 & 2 & 3 & 4 & 5 & 6 & 7 \\
\hline
\end{tabular}




\begin{tabular}{|c|c|c|c|c|c|c|c|}
\hline \multirow[b]{2}{*}{ KEY } & 1 & 2 & 3 & 4 & 5 & 6 & 7 \\
\hline & Never & $\begin{array}{c}\text { At least } \\
\text { once }\end{array}$ & Monthly & $\begin{array}{c}\text { Fort- } \\
\text { nightly }\end{array}$ & Weekly & Daily & Hourly \\
\hline \multicolumn{8}{|c|}{ Threatening comments or behaviours that were intended to threaten harm, intimidate or bully you. } \\
\hline Phone Call & 1 & 2 & 3 & 4 & 5 & 6 & 7 \\
\hline Text Message & 1 & 2 & 3 & 4 & 5 & 6 & 7 \\
\hline Instant Messenger & 1 & 2 & 3 & 4 & 5 & 6 & 7 \\
\hline Social Networking Site & 1 & 2 & 3 & 4 & 5 & 6 & 7 \\
\hline Picture Message & 1 & 2 & 3 & 4 & 5 & 6 & 7 \\
\hline Video Chat & 1 & 2 & 3 & 4 & 5 & 6 & 7 \\
\hline Email & 1 & 2 & 3 & 4 & 5 & 6 & 7 \\
\hline Chatroom & 1 & 2 & 3 & 4 & 5 & 6 & 7 \\
\hline Website/Blog & 1 & 2 & 3 & 4 & 5 & 6 & 7 \\
\hline \multirow[b]{2}{*}{ KEY } & 1 & 2 & 3 & 4 & 5 & 6 & 7 \\
\hline & Never & $\begin{array}{c}\text { At least } \\
\text { once }\end{array}$ & Monthly & $\begin{array}{c}\text { Fort- } \\
\text { nightly }\end{array}$ & Weekly & Daily & Hourly \\
\hline
\end{tabular}

Been contacted to check on you and ask you where you are, what you are doing and who you are with.

\begin{tabular}{|c|c|c|c|c|c|c|c|}
\hline Phone Call & 1 & 2 & 3 & 4 & 5 & 6 & 7 \\
\hline Text Message & 1 & 2 & 3 & 4 & 5 & 6 & 7 \\
\hline Instant Messenger & 1 & 2 & 3 & 4 & 5 & 6 & 7 \\
\hline Social Networking Site & 1 & 2 & 3 & 4 & 5 & 6 & 7 \\
\hline Picture Message & 1 & 2 & 3 & 4 & 5 & 6 & 7 \\
\hline Video Chat & 1 & 2 & 3 & 4 & 5 & 6 & 7 \\
\hline Email & 1 & 2 & 3 & 4 & 5 & 6 & 7 \\
\hline Chatroom & 1 & 2 & 3 & 4 & 5 & 6 & 7 \\
\hline Website/Blog & 1 & 2 & 3 & 4 & 5 & 6 & 7 \\
\hline \multirow[b]{2}{*}{ KEY } & 1 & 2 & 3 & 4 & 5 & 6 & 7 \\
\hline & Never & $\begin{array}{l}\text { At least } \\
\text { once }\end{array}$ & Monthly & $\begin{array}{c}\text { Fort- } \\
\text { nightly }\end{array}$ & Weekly & Daily & Hourly \\
\hline
\end{tabular}

Asked or pressured you to engage in sexual acts or to send messages/pictures that you did not want.

\begin{tabular}{|c|c|c|c|c|c|c|c|}
\hline Phone Call & 1 & 2 & 3 & 4 & 5 & 6 & 7 \\
\hline Text Message & 1 & 2 & 3 & 4 & 5 & 6 & 7 \\
\hline Instant Messenger & 1 & 2 & 3 & 4 & 5 & 6 & 7 \\
\hline Social Networking Site & 1 & 2 & 3 & 4 & 5 & 6 & 7 \\
\hline Picture Message & 1 & 2 & 3 & 4 & 5 & 6 & 7 \\
\hline Video Chat & 1 & 2 & 3 & 4 & 5 & 6 & 7 \\
\hline Email & 1 & 2 & 3 & 4 & 5 & 6 & 7 \\
\hline Chatroom & 1 & 2 & 3 & 4 & 5 & 6 & 7 \\
\hline Website/Blog & 1 & 2 & 3 & 4 & 5 & 6 & 7 \\
\hline \multirow[b]{2}{*}{ KEY } & 1 & 2 & 3 & 4 & 5 & 6 & 7 \\
\hline & Never & $\begin{array}{c}\text { At least } \\
\text { once }\end{array}$ & Monthly & $\begin{array}{c}\text { Fort- } \\
\text { nightly }\end{array}$ & Weekly & Daily & Hourly \\
\hline
\end{tabular}

Been sent sexual or inappropriate messages/pictures etc that you did not want.

\begin{tabular}{|l|lllllll|}
\hline Phone Call & 1 & 2 & 3 & 4 & 5 & 6 & 7 \\
\hline Text Message & 1 & 2 & 3 & 4 & 5 & 6 & 7 \\
\hline Instant Messenger & 1 & 2 & 3 & 4 & 5 & 6 & 7 \\
\hline
\end{tabular}




\begin{tabular}{|l|ccccccc|}
\hline Social Networking Site & 1 & 2 & 3 & 4 & 5 & 6 & 7 \\
\hline Picture Message & 1 & 2 & 3 & 4 & 5 & 6 & 7 \\
\hline Video Chat & 1 & 2 & 3 & 4 & 5 & 6 & 7 \\
\hline Email & 1 & 2 & 3 & 4 & 5 & 6 & 7 \\
\hline Chatroom & 1 & 2 & 3 & 4 & 5 & 6 & 7 \\
\hline Website/Blog & 1 & 2 & 3 & 4 & 5 & 6 & 7 \\
\hline \multicolumn{1}{|c|}{ KEY } & $\mathbf{1}$ & $\mathbf{2}$ & $\mathbf{3}$ & $\mathbf{4}$ & $\mathbf{5}$ & $\mathbf{6}$ & $\mathbf{7}$ \\
\cline { 2 - 8 } & Never & $\begin{array}{c}\text { At least } \\
\text { once }\end{array}$ & Monthly & $\begin{array}{c}\text { Fort- } \\
\text { nightly }\end{array}$ & Weekly & Daily & Hourly \\
\hline
\end{tabular}

Checked your messages, contact histories or friend lists/networks.

\begin{tabular}{|c|c|c|c|c|c|c|c|}
\hline Phone Call & 1 & 2 & 3 & 4 & 5 & 6 & 7 \\
\hline Text Message & 1 & 2 & 3 & 4 & 5 & 6 & 7 \\
\hline Instant Messenger & 1 & 2 & 3 & 4 & 5 & 6 & 7 \\
\hline Social Networking Site & 1 & 2 & 3 & 4 & 5 & 6 & 7 \\
\hline Picture Message & 1 & 2 & 3 & 4 & 5 & 6 & 7 \\
\hline Video Chat & 1 & 2 & 3 & 4 & 5 & 6 & 7 \\
\hline Email & 1 & 2 & 3 & 4 & 5 & 6 & 7 \\
\hline Chatroom & 1 & 2 & 3 & 4 & 5 & 6 & 7 \\
\hline Website/Blog & 1 & 2 & 3 & 4 & 5 & 6 & 7 \\
\hline \multirow[b]{2}{*}{ KEY } & 1 & 2 & 3 & 4 & 5 & 6 & 7 \\
\hline & Never & $\begin{array}{c}\text { At least } \\
\text { once }\end{array}$ & Monthly & $\begin{array}{c}\text { Fort- } \\
\text { nightly }\end{array}$ & Weekly & Daily & Hourly \\
\hline
\end{tabular}

Demanded your passwords to check messages, contact histories or friend lists/networks.

\begin{tabular}{|c|c|c|c|c|c|c|c|}
\hline Phone Call & 1 & 2 & 3 & 4 & 5 & 6 & 7 \\
\hline Text Message & 1 & 2 & 3 & 4 & 5 & 6 & 7 \\
\hline Instant Messenger & 1 & 2 & 3 & 4 & 5 & 6 & 7 \\
\hline Social Networking Site & 1 & 2 & 3 & 4 & 5 & 6 & 7 \\
\hline Picture Message & 1 & 2 & 3 & 4 & 5 & 6 & 7 \\
\hline Video Chat & 1 & 2 & 3 & 4 & 5 & 6 & 7 \\
\hline Email & 1 & 2 & 3 & 4 & 5 & 6 & 7 \\
\hline Chatroom & 1 & 2 & 3 & 4 & 5 & 6 & 7 \\
\hline Website/Blog & 1 & 2 & 3 & 4 & 5 & 6 & 7 \\
\hline \multirow[b]{2}{*}{ KEY } & 1 & 2 & 3 & 4 & 5 & 6 & 7 \\
\hline & Never & $\begin{array}{c}\text { At least } \\
\text { once }\end{array}$ & Monthly & $\begin{array}{c}\text { Fort- } \\
\text { nightly }\end{array}$ & Weekly & Daily & Hourly \\
\hline
\end{tabular}

Deleted or removed contacts or friends or ex-partners.

\begin{tabular}{|l|ccccccc|}
\hline Phone Call & 1 & 2 & 3 & 4 & 5 & 6 & 7 \\
\hline Text Message & 1 & 2 & 3 & 4 & 5 & 6 & 7 \\
\hline Instant Messenger & 1 & 2 & 3 & 4 & 5 & 6 & 7 \\
\hline Social Networking Site & 1 & 2 & 3 & 4 & 5 & 6 & 7 \\
\hline Picture Message & 1 & 2 & 3 & 4 & 5 & 6 & 7 \\
\hline Video Chat & 1 & 2 & 3 & 4 & 5 & 6 & 7 \\
\hline Email & 1 & 2 & 3 & 4 & 5 & 6 & 7 \\
\hline Chatroom & 1 & 2 & 3 & 4 & 5 & 6 & 7 \\
\hline Website/Blog & 1 & 2 & 3 & 4 & 5 & 6 & 7 \\
\multicolumn{1}{|c}{ KEY } & & & & & & & $\mathbf{7}$ \\
\hline & $\mathbf{1}$ & $\mathbf{2}$ & $\mathbf{3}$ & $\mathbf{4}$ & $\mathbf{5}$ & $\mathbf{6}$ & $\mathbf{7}$ \\
\cline { 2 - 9 } & Never & At least & Monthly & Fort- & Weekly & Daily & Hourly \\
\hline
\end{tabular}




\begin{tabular}{|c|c|c|c|c|c|c|c|}
\hline & \multicolumn{3}{|c|}{ once } & \multicolumn{3}{|l|}{ nightly } & \\
\hline \multicolumn{8}{|c|}{ Made you feel afraid not to respond to a call, text, message etc. } \\
\hline Phone Call & 1 & 2 & 3 & 4 & 5 & 6 & 7 \\
\hline Text Message & 1 & 2 & 3 & 4 & 5 & 6 & 7 \\
\hline Instant Messenger & 1 & 2 & 3 & 4 & 5 & 6 & 7 \\
\hline Social Networking Site & 1 & 2 & 3 & 4 & 5 & 6 & 7 \\
\hline Picture Message & 1 & 2 & 3 & 4 & 5 & 6 & 7 \\
\hline Video Chat & 1 & 2 & 3 & 4 & 5 & 6 & 7 \\
\hline Email & 1 & 2 & 3 & 4 & 5 & 6 & 7 \\
\hline Chatroom & 1 & 2 & 3 & 4 & 5 & 6 & 7 \\
\hline Website/Blog & 1 & 2 & 3 & 4 & 5 & 6 & 7 \\
\hline \multirow[b]{2}{*}{ KEY } & 1 & 2 & 3 & 4 & 5 & 6 & 7 \\
\hline & Never & $\begin{array}{c}\text { At least } \\
\text { once }\end{array}$ & Monthly & $\begin{array}{c}\text { Fort- } \\
\text { nightly }\end{array}$ & Weekly & Daily & Hourly \\
\hline \multicolumn{8}{|c|}{ Prevented you from using electronic communication technology or from talking to others. } \\
\hline Phone Call & 1 & 2 & 3 & 4 & 5 & 6 & 7 \\
\hline Text Message & 1 & 2 & 3 & 4 & 5 & 6 & 7 \\
\hline Instant Messenger & 1 & 2 & 3 & 4 & 5 & 6 & 7 \\
\hline Social Networking Site & 1 & 2 & 3 & 4 & 5 & 6 & 7 \\
\hline Picture Message & 1 & 2 & 3 & 4 & 5 & 6 & 7 \\
\hline Video Chat & 1 & 2 & 3 & 4 & 5 & 6 & 7 \\
\hline Email & 1 & 2 & 3 & 4 & 5 & 6 & 7 \\
\hline Chatroom & 1 & 2 & 3 & 4 & 5 & 6 & 7 \\
\hline Website/Blog & 1 & 2 & 3 & 4 & 5 & 6 & 7 \\
\hline
\end{tabular}


Table 6

Descriptive frequencies of the 12 TAADVA victimisation behaviours and nine ECTs $(n=277)$

\begin{tabular}{|c|c|c|c|c|c|c|c|c|c|c|c|c|c|c|c|c|c|c|c|c|c|}
\hline & \multicolumn{7}{|c|}{ Total \% (n) } & \multicolumn{7}{|c|}{ Male \% (n) } & \multicolumn{7}{|c|}{ Female \% (n) } \\
\hline & $\mathbf{N}^{*}$ & $\mathbf{O}$ & $\mathbf{M}$ & $\mathbf{F}$ & $\mathbf{W}$ & D & $\mathbf{H}$ & $\mathbf{N}$ & $\mathbf{O}$ & $\mathbf{M}$ & $\mathbf{F}$ & $\mathbf{W}$ & $\mathbf{D}$ & $\mathbf{H}$ & $\mathbf{N}$ & $\mathbf{O}$ & $\mathbf{M}$ & $\mathbf{F}$ & $\mathbf{W}$ & D & $\mathbf{H}$ \\
\hline \multicolumn{22}{|l|}{ Insults } \\
\hline \multirow[t]{2}{*}{ Phone call } & 74.4 & 14.1 & 1.8 & 2.9 & 3.2 & 2.5 & 1.1 & 78.3 & 10 & 1.7 & 2.5 & 4.2 & 1.7 & 1.7 & 71.3 & 17.2 & 1.9 & 3.2 & 2.5 & 3.2 & .6 \\
\hline & (206) & (39) & (5) & (8) & (9) & (7) & (3) & (94) & (12) & (2) & (3) & $(5)$ & (2) & (2) & (112) & (27) & (3) & (5) & (4) & $(5)$ & (1) \\
\hline \multirow[t]{2}{*}{ Text message } & 62.1 & 18.4 & 4.3 & 2.2 . & 5.4 & 2.9 & 4.7 & 66.7 & 15 & 5 & 1.7 & 4.2 & 2.5 & 5 & 58.6 & 21 & 3.8 & 2.5 & 6.4 & 3.2 & 4.5 \\
\hline & $(172)$ & $(51)$ & (12) & (6) & (15) & (8) & (13) & $(80)$ & (18) & (6) & (2) & $(5)$ & (3) & (6) & (92) & (33) & (6) & (4) & (10) & $(5)$ & (7) \\
\hline \multirow[t]{2}{*}{ Instant messenger } & 71.1 & 13 & 2.9 & 3.2 & 4 & 2.2 & 3.6 & 72.5 & 10.8 & 3.3 & 3.3 & 3.3 & 3.3 & 3.3 & 70.1 & 14.6 & 2.5 & 3.2 & 4.5 & 1.3 & 3.8 \\
\hline & (197) & (36) & (8) & (9) & (11) & (6) & (10) & $(87)$ & (13) & (4) & (4) & (4) & (4) & (4) & (110) & (23) & (4) & (5) & (7) & (2) & (6) \\
\hline \multirow[t]{2}{*}{ Social networking site } & 69 & 14.4 & 4.3 & 2.5 & 4 & 2.2 & 3.6 & 72.5 & 11.7 & 5.8 & 1.7 & 1.7 & 3.3 & 3.3 & 66.2 & 16.6 & 3.2 & 3.2 & 5.7 & 1.3 & 3.8 \\
\hline & (191) & $(40)$ & (12) & (7) & (11) & (6) & (10) & (87) & (14) & (7) & (2) & (2) & (4) & (4) & (104) & (26) & (5) & (5) & (9) & (2) & (6) \\
\hline \multirow[t]{2}{*}{ Picture message } & 84.1 & 6.1 & 2.2 & 2.2 & 1.4 & 1.8 & 2.2 & 82.5 & 9.2 & 1.7 & .8 & 1.7 & 1.7 & 2.5 & 85.4 & 3.8 & 2.5 & 3.2 & 1.3 & 1.9 & 1.9 \\
\hline & (233) & (17) & (6) & (6) & (4) & (5) & (6) & (99) & (11) & (2) & (1) & $(2)$ & (2) & (3) & (134) & (6) & (4) & (5) & (2) & (3) & (3) \\
\hline \multirow[t]{2}{*}{ Video chat } & 85.9 & 5.1 & 1.8 & 1.8 & 2.5 & 1.8 & 1.1 & 79.2 & 6.7 & 3.3 & 4.2 & 4.2 & .8 & 1.7 & 91.1 & 3.8 & .6 & 0 & 1.3 & 2.5 & .6 \\
\hline & (238) & (14) & (5) & (5) & (7) & (5) & (3) & (95) & (8) & (4) & (5) & (5) & (1) & (2) & (143) & (6) & (1) & (0) & (2) & (4) & (1) \\
\hline \multirow[t]{2}{*}{ Email } & 94.2 & 2.9 & .4 & .7 & .7 & 0 & 1.1 & 90 & 4.2 & .8 & 1.7 & .8 & 0 & 2.5 & 97.5 & 1.9 & 0 & 0 & .6 & 0 & 0 \\
\hline & (261) & (8) & (1) & (2) & (2) & (0) & (3) & (108) & (5) & (1) & (2) & (1) & (0) & (3) & (153) & (3) & (0) & (0) & (1) & $(0)$ & (0) \\
\hline
\end{tabular}




\begin{tabular}{|c|c|c|c|c|c|c|c|c|c|c|c|c|c|c|c|c|c|c|c|c|c|}
\hline Chatroom & 92.1 & 4.3 & .4 & 1.1 & 0 & 1.1 & 1.1 & 90.8 & 4.2 & 0 & 1.7 & 0 & .8 & 2.5 & 93 & 4.5 & .6 & .6 & 0 & 1.3 & 0 \\
\hline & $(255)$ & (12) & (1) & (3) & $(0)$ & (3) & (3) & (109) & (5) & $(0)$ & (2) & $(0)$ & (1) & (3) & (146) & (7) & (1) & (1) & $(0)$ & (2) & (0) \\
\hline Website/Blog & 91.3 & 4 & .7 & .4 & .4 & 1.4 & 1.8 & 85.8 & 6.7 & .8 & .8 & .8 & 1.7 & 3.3 & 95.5 & 1.9 & .6 & 0 & 0 & 1.3 & .6 \\
\hline & $(253)$ & (11) & (2) & (1) & (1) & (4) & (5) & (103) & (8) & (1) & (1) & (1) & (2) & (4) & (150) & (3) & (1) & $(0)$ & $(0)$ & (2) & (1) \\
\hline \multicolumn{22}{|l|}{ Embarassment/Humiliation } \\
\hline \multirow[t]{2}{*}{ Phone call } & 83.4 & 9 & 1.4 & 1.4 & 1.8 & 1.1 & 1.8 & 85 & 9.2 & 1.7 & 1.7 & .8 & 0 & 1.7 & 82.2 & 8.9 & 1.3 & 1.3 & 2.5 & 1.9 & 1.9 \\
\hline & $(231)$ & $(25)$ & (4) & (4) & (5) & (3) & (5) & (102) & (11) & (2) & (2) & (1) & (0) & (2) & (129) & (14) & (2) & (2) & (4) & (3) & (3) \\
\hline \multirow[t]{2}{*}{ Text message } & 77.6 & 10.5 & 4.3 & 2.5 & 2.5 & .4 & 2.2 & 90 & 7.5 & 5.8 & 1.7 & 2.5 & 0 & 2.5 & 75.8 & 12.7 & 3.2 & 3.2 & 2.5 & .6 & 1.9 \\
\hline & $(215)$ & (29) & (12) & (7) & (7) & (1) & (6) & (96) & (9) & (7) & (2) & (3) & $(0)$ & (3) & (119) & $(20)$ & (5) & $(5)$ & (4) & (1) & (3) \\
\hline \multirow[t]{2}{*}{ Instant messenger } & 82.7 & 7.6 & 3.2 & 2.9 & 1.4 & 1.1 & 1.1 . & 82.5 & 8.3 & 3.3 & 3.3 & .8 & .8 & .8 & 82.8 & 7 & 3.2 & 2.5 & 1.9 & 1.3 & 1.3 \\
\hline & $(229)$ & $(21)$ & (9) & (8) & (4) & (3) & (3) & (99) & (10) & (4) & (4) & (1) & (1) & $(1)$ & (130) & (11) & (5) & (4) & (3) & (2) & (2) \\
\hline \multirow[t]{2}{*}{ Social networking site } & 77.3 & 12.3 & 2.5 & 3.6 & 1.8 & 1.8 & .7 & 78.3 & 10.8 & 3.3 & 4.2 & 1.7 & 1.7 & 0 & 76.4 & 13.4 & 1.9 & 3.2 & 1.9 & 1.9 & 1.3 \\
\hline & (214) & (34) & (7) & $(10)$ & $(5)$ & (5) & (2) & (94) & (13) & (4) & $(5)$ & (2) & (2) & $(0)$ & (120) & $(21)$ & (3) & $(5)$ & (3) & (3) & (2) \\
\hline \multirow[t]{2}{*}{ Picture message } & 87 & 5.8 & 1.4 & 2.5 & 1.4 & 1.4 & .4 & 87.5 & 5.8 & 1.7 & 2.5 & 1.7 & .8 & 0 & 86.6 & 5.7 & 1.3 & 2.5 & 1.3 & 1.9 & .6 \\
\hline & (241) & (16) & (4) & (7) & (4) & (4) & (1) & (105) & (7) & (2) & (3) & (2) & (1) & $(0)$ & (136) & (9) & (2) & (4) & (2) & (3) & (1) \\
\hline \multirow[t]{2}{*}{ Video chat } & 91 & 5.1 & 1.1 & 1.4 & 0 & 1.1 & .4 & 88.3 & 5.8 & 2.5 & 1.7 & 0 & 1.7 & 0 & 93 & 4.5 & 0 & 1.3 & 0 & .6 & .6 \\
\hline & $(252)$ & (14) & (3) & (4) & $(0)$ & (3) & (1) & (106) & (7) & (3) & (2) & $(0)$ & (2) & $(0)$ & (146) & (7) & $(0)$ & (2) & $(0)$ & (1) & (1) \\
\hline \multirow[t]{2}{*}{ Email } & 93.5 & 4 & .4 & 1.1 & .4 & .7 & 0 & 90.8 & 5 & .8 & 1.7 & .8 & .8 & 0 & 95.5 & 3.2 & 0 & .6 & 0 & .6 & 0 \\
\hline & (259) & (11) & (1) & (3) & (1) & (2) & $(0)$ & (109) & (6) & (1) & (2) & (1) & (1) & $(0)$ & (150) & (5) & $(0)$ & (1) & $(0)$ & (1) & (0) \\
\hline Chatroom & 92.1 & 4.7 & .4 & 1.1 & .7 & .7 & .4 & 91.7 & 4.2 & .8 & 1.7 & .8 & .8 & 0 & 92.4 & 5.1 & 0 & .6 & .6 & .6 & .6 \\
\hline
\end{tabular}




\begin{tabular}{|c|c|c|c|c|c|c|c|c|c|c|c|c|c|c|c|c|c|c|c|c|c|}
\hline \multirow{3}{*}{ Website/Blog } & $(255)$ & (13) & (1) & (3) & (2) & (2) & (1) & $(110)$ & (5) & (1) & (2) & (1) & (1) & (0) & (145) & (8) & (0) & (1) & (1) & (1) & (1) \\
\hline & 91.7 & 5.1 & 0 & .7 & 1.1 & .7 & .7 & 88.3 & 7.5 & 0 & .8 & 2.5 & .8 & 0 & 94.3 & 3.2 & 0 & .6 & 0 & .6 & 1.3 \\
\hline & (254) & (14) & $(0)$ & (2) & (3) & (2) & (2) & (106) & (9) & $(0)$ & (1) & (3) & (1) & $(0)$ & (136) & (5) & $(0)$ & (1) & $(0)$ & (1) & (2) \\
\hline \multicolumn{22}{|l|}{ Shared /distribute ${ }^{\mathrm{a}}$} \\
\hline \multirow{2}{*}{ Phone call } & 87 & 6.5 & 2.5 & 1.1 & 1.1 & 1.1 & .7 & 87.4 & 3.4 & 3.4 & 1.7 & 1.7 & 1.7 & .8 & 86.6 & 8.9 & 1.9 & .6 & .6 & .6 & .6 \\
\hline & $(240)$ & (18) & (7) & (3) & (3) & (3) & (2) & $(104)$ & (4) & (4) & (2) & (2) & (2) & (1) & (136) & (14) & (3) & (1) & (1) & (1) & (1) \\
\hline \multirow[t]{2}{*}{ Text message } & 77.9 & 11.2 & 3.3 & 3.6 & 1.8 & 1.1 & 1.1 & 80.7 & 7.6 & 3.4 & 4.2 & .8 & 1.7 & 1.7 & 75.8 & 14 & 3.2 & 3.2 & 2.5 & .6 & .6 \\
\hline & $(215)$ & $(31)$ & (9) & (10) & (5) & (3) & (3) & (96) & (9) & (4) & (5) & (1) & (2) & (2) & (119) & $(22)$ & (5) & (5) & (4) & (1) & (1) \\
\hline \multirow[t]{2}{*}{ Instant messenger } & 85.1 & 7.2 & 1.4 & 1.4 & 1.4 & 2.2 & 1.1 & 84.9 & 6.7 & 1.7 & 1.7 & 0 & 4.2 & .8 & 85.4 & 7.6 & 1.3 & 1.3 & 2.5 & .6 & 1.3 \\
\hline & $(235)$ & (20) & (4) & (4) & (4) & (6) & (3) & $(101)$ & (8) & (2) & (2) & $(0)$ & (5) & (1) & (134) & (12) & (2) & (2) & (4) & (1) & (2) \\
\hline \multirow[t]{2}{*}{ Social networking site } & 84.8 & 6.2 & 1,8 & 2.2 & 2.5 & 1.1 & 1.4 & 84.9 & 5 & 2.5 & 2.5 & 1.7 & 1.7 & 1.7 & 84.7 & 7 & 1.3 & 1.9 & 3.2 & .6 & 1.3 \\
\hline & (234) & (17) & (5) & (6) & (7) & (3) & (4) & $(101)$ & (6) & (3) & (3) & (2) & (2) & (2) & (133) & (11) & (2) & (3) & $(5)$ & (1) & (2) \\
\hline \multirow[t]{2}{*}{ Picture message } & 87 & 5.8 & 1.4 & 1.8 & 2.2 & .7 & 1.1 & 85.7 & 6.7 & 2.5 & 1.7 & 1.7 & .8 & .8 & 87.9 & 5.1 & .6 & 1.9 & 2.5 & .6 & 1.3 \\
\hline & $(240)$ & (26) & (4) & (5) & (6) & (2) & (3) & (102) & (8) & (3) & (2) & (2) & (1) & (1) & (138) & (8) & (1) & (3) & (4) & (1) & (2) \\
\hline \multirow[t]{2}{*}{ Video chat } & 93.1 & 1.8 & .7 & 1.8 & .7 & 1.1 & .7 & 89.9 & 2.5 & .8 & 3.4 & .8 & 1.7 & .8 & 95.5 & 1.3 & .6 & .6 & .6 & .6 & .6 \\
\hline & $(257$ & (5) & (2) & (5) & (2) & (3) & (2) & (107) & (3) & (1) & (4) & (1) & (2) & (1) & $(150)$ & (2) & (1) & (1) & (1) & (1) & (1) \\
\hline \multirow[t]{2}{*}{ Email } & 93.5 & 3.6 & .4 & .7 & .7 & .7 & .4 & 89.9 & 5.9 & .8 & 0 & .8 & 1.7 & .8 & 96.2 & 1.9 & 0 & 1.3 & .6 & 0 & 0 \\
\hline & (258) & (10) & (1) & (2) & (2) & (2) & (1) & (107) & (7) & (1) & $(0)$ & (1) & (2) & (1) & (151) & (3) & $(0)$ & (2) & (1) & $(0)$ & (0) \\
\hline \multirow[t]{2}{*}{ Chatroom } & 94.6 & 1.4 & .7 & 1.1 & 1.1 & 0 & 1.1 & 92.4 & 1.7 & .8 & .8 & 1.7 & 0 & 2.5 & 96.2 & 1.3 & .6 & 1.3 & .6 & 0 & 0 \\
\hline & $(261$ & (4) & (2) & (3) & (3) & $(0)$ & (3) & (110) & (2) & (1) & (1) & (2) & $(0)$ & (3) & (151) & (2) & (1) & (2) & (1) & $(0)$ & (0) \\
\hline
\end{tabular}




\begin{tabular}{|c|c|c|c|c|c|c|c|c|c|c|c|c|c|c|c|c|c|c|c|c|c|}
\hline Website/Blog & 93.8 & 1.4 & 1.4 & 1.1 & .7 & .4 & 1.1 & 92.4 & .8 & 1.7 & 1.7 & .8 & .8 & 1.7 & 94.9 & 1.9 & 1.3 & .6 & .6 & 0 & .6 \\
\hline & $(259)$ & (4) & (4) & (3) & (2) & (1) & (3) & (110) & (1) & (2) & (2) & (1) & (1) & (2) & (149) & (3) & (2) & (1) & (1) & $(0)$ & (1) \\
\hline \multicolumn{22}{|l|}{ Threat } \\
\hline \multirow[t]{2}{*}{ Phone call $^{\mathrm{a}}$} & 88 & 6.9 & 1.1 & .7 & 1.1 & 1.8 & .4 & 90.8 & 4.2 & 1.7 & .8 & .8 & 1.7 & 0 & 86 & 8.9 & .6 & .6 & 1.3 & 1.9 & .6 \\
\hline & $(243)$ & (19) & (3) & (2) & (3) & (5) & (1) & (108) & (5) & (2) & (1) & (1) & (2) & $(0)$ & (135) & (14) & (1) & (1) & (2) & (3) & (1) \\
\hline \multirow[t]{2}{*}{ Text message $^{b}$} & 83.6 & 9.1 & 1.8 & 1.5 & 2.5 & .4 & 1.1 & 88.1 & 4.2 & 2.5 & 2.5 & 1.7 & 0 & .8 & 80.3 & 12.7 & 1.3 & .6 & 3.2 & .6 & 1.3 \\
\hline & $(230)$ & $(25)$ & $(5)$ & (4) & (7) & (1) & (3) & (104) & (5) & (3) & (3) & (2) & $(0)$ & (1) & (126) & $(20)$ & $(2)$ & $(1)$ & $(5)$ & (1) & (2) \\
\hline \multirow{2}{*}{ Instant messenger ${ }^{b}$} & 88.7 & 6.5 & 1.1 & .7 & 1.1 & 1.1 & .7 & 89.8 & 5.9 & 1.7 & .8 & .8 & 0 & .8 & 87.9 & 7 & .6 & .6 & 1.3 & 1.9 & .6 \\
\hline & $(244)$ & $(18)$ & (3) & $(2)$ & (3) & (3) & (2) & (106) & (7) & $(2)$ & (1) & (1) & $(0)$ & (1) & $(138)$ & (11) & (1) & $(1)$ & $(2)$ & (3) & (1) \\
\hline \multirow[t]{2}{*}{ Social networking site ${ }^{b}$} & 86.5 & 7.6 & 1.8 & .7 & 1.1 & .7 & 1.5 & 89.8 & 4.2 & 3.4 & .8 & 0 & .8 & .8 & 84.1 & 10.2 & .6 & .6 & 1.9 & .6 & 1.9 \\
\hline & $(238)$ & $(21)$ & (5) & (2) & (3) & $(2)$ & (4) & (106) & (5) & (4) & (1) & $(0)$ & (1) & (1) & (132) & (16) & (1) & (1) & (3) & (1) & (3) \\
\hline \multirow[t]{2}{*}{ Picture message $^{\mathrm{b}}$} & 93.5 & 3.3 & .4 & .7 & .7 & .4 & 1.1 & 91.5 & 4.2 & .8 & 1.7 & .8 & 0 & .8 & 94.9 & 2.5 & 0 & 0 & .6 & .6 & 1.3 \\
\hline & $(257)$ & (9) & (1) & (2) & (2) & (1) & (3) & (108) & (5) & (1) & (2) & (1) & (0) & (1) & (149) & (4) & $(0)$ & $(0)$ & (1) & (1) & (2) \\
\hline \multirow[t]{2}{*}{ Video chat ${ }^{\mathrm{b}}$} & 94.5 & 3.3 & 1.1 & 0 & 0 & .4 & .7 & 91.5 & 5.1 & 2.5 & 0 & 0 & 0 & .8 & 96.8 & 1.9 & 0 & 0 & 0 & .6 & .6 \\
\hline & $(260)$ & (9) & (3) & $(0)$ & (0) & (1) & (2) & (108) & (6) & (3) & (0) & $(0)$ & $(0)$ & (1) & $(152)$ & (3) & $(0)$ & $(0)$ & $(0)$ & (1) & (1) \\
\hline \multirow[t]{2}{*}{ Email $^{\mathrm{b}}$} & 94.9 & 2.9 & .7 & .4 & 0 & .7 & .4 & 92.4 & 4.2 & .8 & .8 & 0 & .8 & .8 & 96.8 & 1.9 & .6 & 0 & 0 & .6 & 0 \\
\hline & $(261)$ & (8) & (2) & (1) & $(0)$ & (2) & (1) & (109) & (5) & (1) & (1) & $(0)$ & (1) & (1) & $(152)$ & (3) & (1) & $(0)$ & $(0)$ & (1) & (0) \\
\hline \multirow[t]{2}{*}{ Chatroom $^{\mathrm{b}}$} & 95.3 & 2.5 & .4 & .4 & 0 & .7 & .7 & 93.2 & 3.4 & .8 & .8 & 0 & .8 & .8 & 96.8 & 1.9 & 0 & 0 & 0 & .6 & .6 \\
\hline & $(262)$ & (7) & (1) & (1) & $(0)$ & (2) & (2) & (110) & (4) & (1) & (1) & $(0)$ & (1) & (1) & $(152)$ & (3) & $(0)$ & $(0)$ & $(0)$ & (1) & (1) \\
\hline Website/Blog & 94.9 & 2.5 & 1.1 & .4 & 0 & .4 & .7 & 93.2 & 2.5 & 2.5 & .8 & 0 & 0 & .8 & 96.2 & 2.5 & 0 & 0 & 0 & .6 & .6 \\
\hline
\end{tabular}




$$
\text { (261) }
$$$$
\text { (7) }
$$$$
\text { (1) }
$$$$
\text { (1) (2) }
$$$$
\text { (110) (3) }
$$$$
\text { (3) (1) (0) }
$$$$
\text { (0) (1) }
$$$$
\text { (151) }
$$$$
\text { (4) }
$$$$
\text { (0) (0) (1) (1) }
$$

Checked up on ${ }^{\mathrm{a}}$

\begin{tabular}{|c|c|c|c|c|c|c|c|c|c|c|c|c|c|c|c|c|c|c|c|c|c|}
\hline \multirow[t]{2}{*}{ Phone call } & 58.7 & 15.9 & 4.3 & 5.1 & 7.6 & 5.1 & 3.3 & 55.5 & 13.4 & 6.7 & 7.6 & 7.6 & 3.4 & 5.9 & 61.1 & 17.8 & 2.5 & 3.2 & 7.6 & 6.4 & 1.3 \\
\hline & $(162)$ & (44) & (12) & (14) & (21) & (14) & (9) & (66) & (16) & (8) & (9) & (9) & (4) & (7) & (96) & (28) & (4) & (5) & (12) & (10) & (2) \\
\hline \multirow[t]{2}{*}{ Text message } & 52.2 & 21.4 & 4.7 & 4.3 & 6.2 & 8.3 & 2.9 & 50.4 & 17.6 & 6.7 & 5 & 9.2 & 6.9 & 5 & 53.5 & 24.2 & 3.2 & 3.8 & 3.8 & 10.2 & 1.3 \\
\hline & (144) & (59) & (13) & (12) & (17) & $(23$ & $(8)$ & $(60)$ & (21) & $(8)$ & (6) & (11) & (7) & (6) & $(84)$ & (38) & $(5)$ & (6) & $(6)$ & (16) & (2) \\
\hline \multirow[t]{2}{*}{ Instant messenger } & 68.1 & 14.5 & 3.6 & 3.6 & 3.3 . & 5.1 & 1.8 & 63.9 & 14.3 & 3.4 & 6.7 & 4.2 & 4.2 & 3.4 & 71.3 & 14.6 & 3.8 & 1.3 & 2.5 & 5.7 & .6 \\
\hline & (188) & $(40)$ & (10) & (10) & $(9)$ & (14) & (5) & (76) & (17) & (4) & (8) & (5) & (5) & (4) & (112) & (26) & $(6)$ & (2) & (4) & (9) & (1) \\
\hline \multirow[t]{2}{*}{ Social networking site } & 75.4 & 9.1 & 3.3 & 2.9 & 2.2 & 5.1 & 2.2 & 73.1 & 8.4 & 5 & 4.2 & 2.5 & 2.5 & 4.2 & 77.1 & 9.6 & 1.9 & 1.9 & 1.9 & 7 & .6 \\
\hline & $(208)$ & $(25)$ & (9) & $(8)$ & $(6)$ & (14) & $(6)$ & $(87)$ & (10) & $(6)$ & $(5)$ & (3) & (3) & (5) & (121) & $(15)$ & (3) & (3) & (3) & (11) & (1) \\
\hline \multirow[t]{2}{*}{ Picture message } & 85.1 & 4.3 & 2.5 & 2.2 & 1.1 & 2.9 & 1.8 & 77.3 & 5 & 5 & 5 & 2.5 & .8 & 4.2 & 91.1 & 3.8 & .6 & 0 & 0 & 4.5 & 0 \\
\hline & $(235)$ & (12) & (7) & $(6)$ & (3) & $(8)$ & $(5)$ & $(92)$ & $(6)$ & $(6)$ & (6) & (3) & (1) & $(5)$ & (143) & $(6)$ & (1) & $(0)$ & $(0)$ & (7) & (0) \\
\hline \multirow[t]{2}{*}{ Video chat } & 88.4 & 4.7 & 1.8 & 1.8 & .7 & 1.4 & 1.1 & 80.7 & 8.4 & 2.5 & 4.2 & 1.7 & 0 & 2.5 & 94.3 & 1.9 & 1.3 & 0 & 0 & 2.5 & 0 \\
\hline & $(244)$ & (13) & (5) & $(5)$ & (2) & $(4)$ & (3) & (96) & (10) & (3) & (5) & (2) & $(0)$ & (3) & (148) & (3) & (2) & $(0)$ & $(0)$ & (4) & (0) \\
\hline \multirow[t]{2}{*}{ Email } & 92 & 3.3 & .7 & 1.1 & 1.1 & 1.1 & .7 & 88.2 & 4.2 & 1.7 & 2.5 & 1.7 & 0 & 1.7 & 94.9 & 2.5 & 0 & 0 & .6 & 1.9 & 0 \\
\hline & (254) & (9) & (2) & (3) & (3) & (3) & (2) & (105) & $(5)$ & (2) & (3) & (2) & $(0)$ & $(2)$ & (149) & (4) & $(0)$ & (0) & (1) & (3) & (0) \\
\hline \multirow[t]{2}{*}{ Chatroom } & 91.7 & 2.5 & 1.1 & 1.4 & .7 & 1.8 & .7 & 87.4 & 3.4 & 1.7 & 3.4 & 1.7 & .8 & 1.7 & 94.9 & 1.9 & .6 & 0 & 0 & 2.5 & 0 \\
\hline & $(253$ & (7) & (3) & $(4)$ & (2) & $(5)$ & (2) & (104) & (4) & (2) & (4) & (2) & (1) & $(2)$ & (149) & (3) & (1) & (0) & $(0)$ & (4) & (0) \\
\hline \multirow[t]{2}{*}{ Website/Blog } & 91.3 & 2.9 & 1.4 & 1.8 & .4 & 1.1 & 1.1 & 86.6 & 3.4 & 3.4 & 4.2 & .8 & 0 & 1.7 & 94.9 & 2.5 & 0 & 0 & 0 & 1.9 & .6 \\
\hline & $(252)$ & (8) & (4) & $(5)$ & $(1)$ & (3) & (3) & (103) & $(4)$ & (4) & $(5)$ & (1) & $(0)$ & (2) & (149) & (4) & $(0)$ & $(0)$ & $(0)$ & (3) & (1) \\
\hline
\end{tabular}




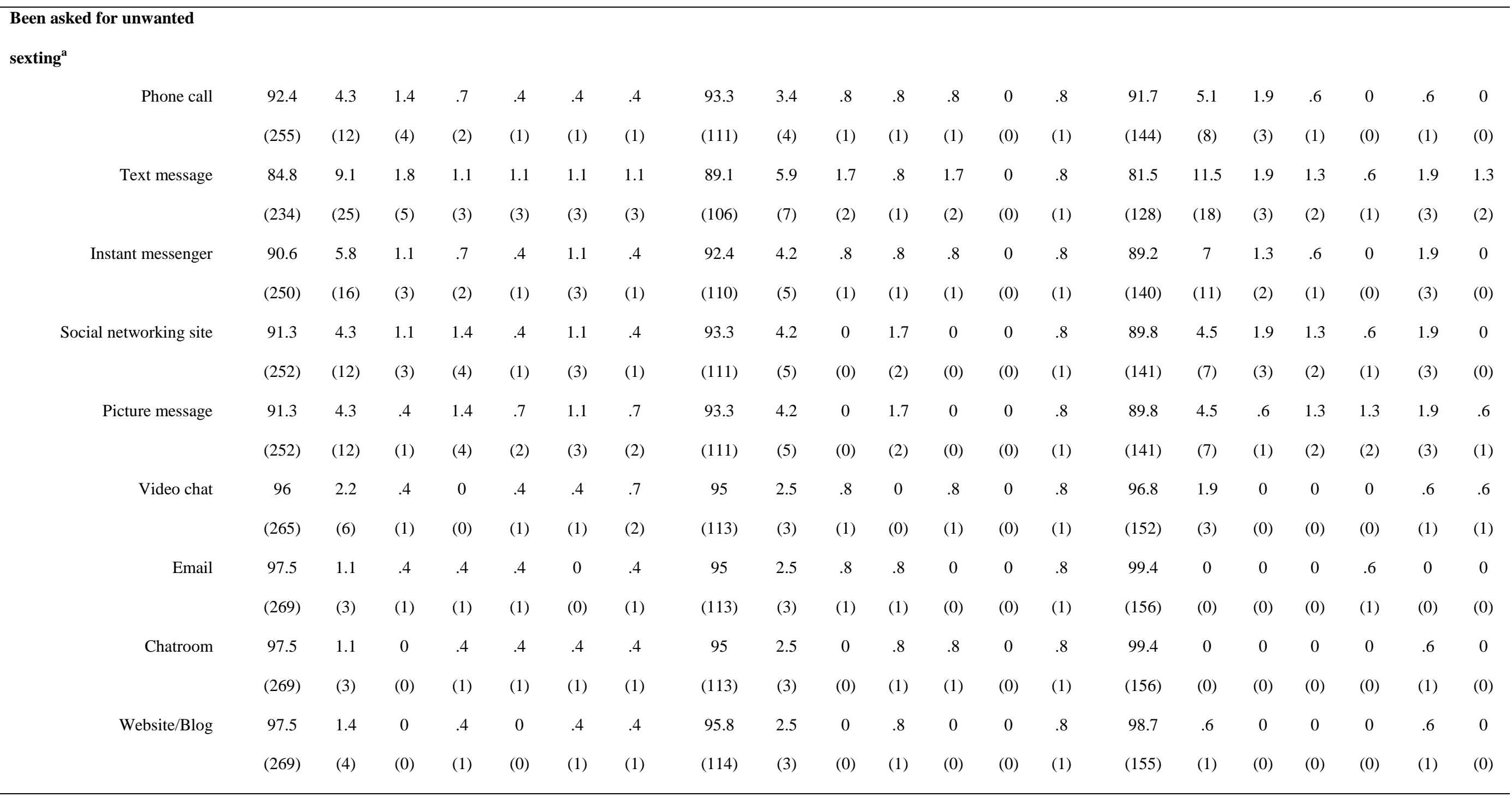




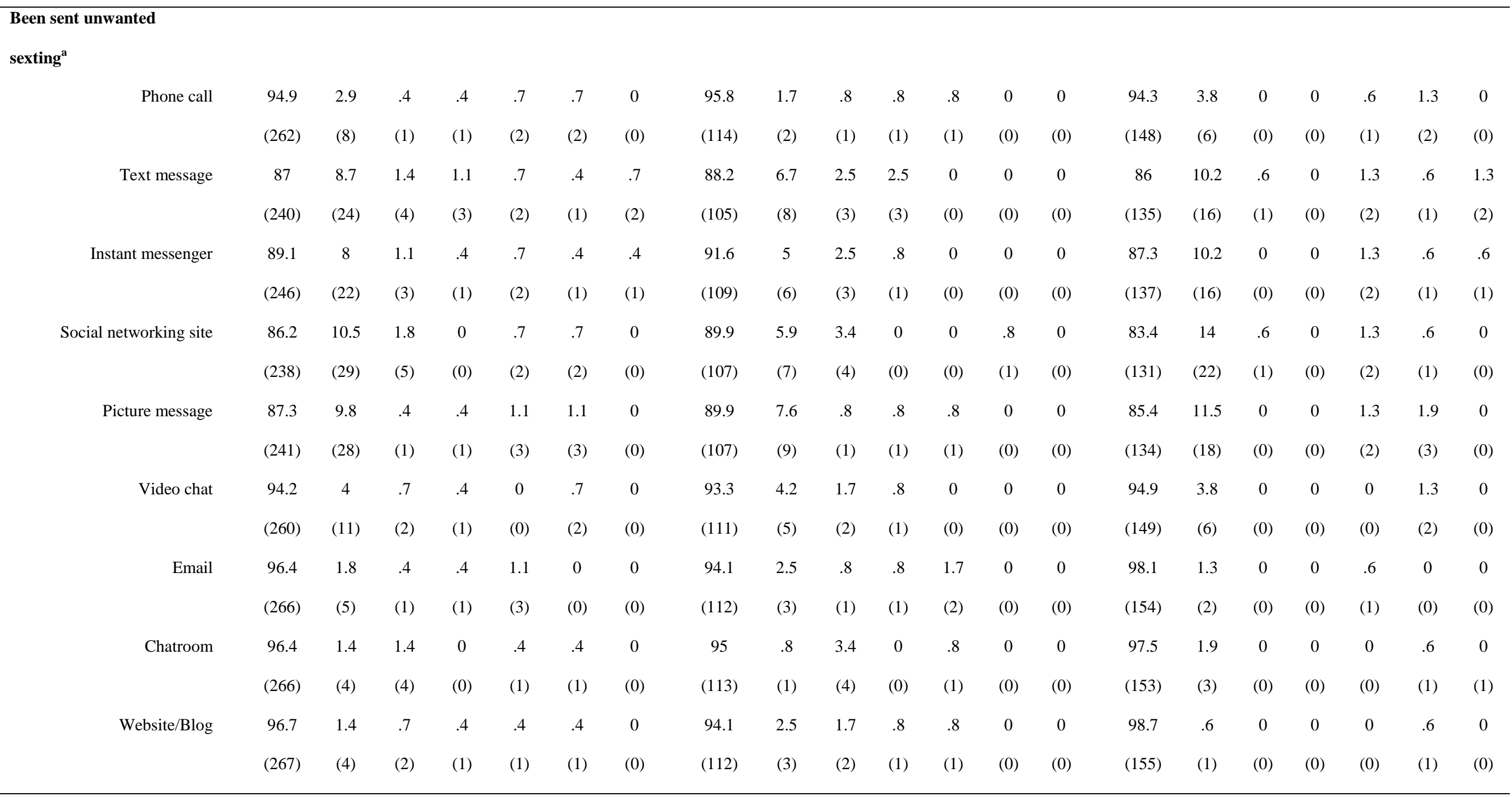




\begin{tabular}{|c|c|c|c|c|c|c|c|c|c|c|c|c|c|c|c|c|c|c|c|c|c|}
\hline Checked messages & & & & & & & & & & & & & & & & & & & & & \\
\hline \multirow[t]{2}{*}{ Phone call ${ }^{\mathrm{b}}$} & 78.9 & 9.5 & 2.5 & 2.5 & 1.1 & 2.5 & 2.9 & 72 & 12.7 & .8 & 2.5 & .8 & 5.1 & 5.9 & 84.1 & 7 & 3.8 & 2.5 & 1.3 & .6 & 6 \\
\hline & (217) & (26) & (7) & (7) & (3) & (7) & (8) & $(85)$ & (15) & (1) & (3) & (1) & (6) & (7) & (132) & (11) & (6) & (4) & (2) & (1) & (1) \\
\hline \multirow[t]{2}{*}{ Text message $^{\mathrm{b}}$} & 72.4 & 14.2 & 2.9 & 2.2 & 2.2 & 3.6 & 2.5 & 68.6 & 12.7 & 2.5 & 2.5 & 2.5 & 6.8 & 4.2 & 75.2 & 15.3 & 3.2 & 1.9 & 1.9 & 1.3 & 1.3 \\
\hline & (199) & (39) & (8) & (6) & (6) & (10) & (7) & $(81)$ & (15) & (3) & (3) & (3) & (8) & (5) & (118) & (24) & (5) & (3) & (3) & (2) & (2) \\
\hline \multirow[t]{2}{*}{ Instant messenger ${ }^{c}$} & 78.1 & 11.3 & 2.2 & 1.8 & 1.8 & 2.6 & 2.2 & 70.9 & 12.8 & 1.7 & 3.4 & 1.7 & 5.1 & 4.3 & 83.4 & 10.2 & 2.5 & .6 & 1.9 & .6 & 6 \\
\hline & (214) & $(31)$ & (6) & (5) & (5) & (7) & (6) & $(83)$ & $(15)$ & (2) & (4) & (2) & (6) & (5) & (131) & (16) & (4) & (1) & (3) & (1) & (1) \\
\hline \multirow[t]{2}{*}{ Social networking site ${ }^{\mathrm{b}}$} & 75.6 & 10.9 & 1.8 & 2.5 & 3.3 & 3.6 & 2.2 & 70.3 & 12.7 & 1.7 & 2.5 & 1.7 & 6.8 & 4.2 & 79.6 & 9.6 & 1.9 & 2.5 & 4.5 & 1.3 & .6 \\
\hline & $(208)$ & $(30)$ & (5) & (7) & (9) & $(10)$ & (6) & $(83)$ & (15) & (2) & (3) & (2) & (8) & (5) & $(125)$ & $(15)$ & (3) & (4) & (7) & (2) & (1) \\
\hline \multirow[t]{2}{*}{ Picture message $^{\mathrm{b}}$} & 84.7 & 6.2 & 1.8 & 1.5 & 1.5 & 2.2 & 2.2 & 78.8 & 8.5 & .8 & 2.5 & 1.7 & 3.4 & 4.2 & 89.2 & 4.5 & 2.5 & .6 & 1.3 & 1.3 & .6 \\
\hline & (233) & (17) & (5) & (4) & (4) & (6) & (6) & (93) & (10) & (1) & (3) & (2) & (4) & (5) & (140) & (7) & (4) & (1) & (2) & (2) & (1) \\
\hline \multirow[t]{2}{*}{ Video chat ${ }^{\mathrm{b}}$} & 88.7 & 4.4 & 1.8 & 1.1 & .4 & 1.8 & 1.8 & 82.2 & 7.6 & .8 & 1.7 & .8 & 3.4 & 3.4 & 93.6 & 1.9 & 2.5 & .6 & 0 & .6 & .6 \\
\hline & (244) & (12) & (5) & (3) & (1) & (5) & (5) & (97) & (9) & (1) & (2) & (1) & (4) & (4) & (147) & (3) & (4) & (1) & (0) & (1) & (1) \\
\hline \multirow[t]{2}{*}{ Email $^{\mathrm{b}}$} & 88 & 5.8 & 1.1 & 1.5 & .7 & 1.8 & 1.1 & 81.4 & 9.3 & 0 & 2.5 & .8 & 3.4 & 2.5 & 93 & 3.2 & 1.9 & .6 & .6 & .6 & .6 \\
\hline & (242) & (16) & (3) & (4) & (2) & (5) & (3) & (96) & (11) & (0) & (3) & (1) & (4) & (3) & (146) & (5) & (3) & (1) & (1) & (1) & (1) \\
\hline \multirow[t]{2}{*}{ Chatroom $^{\mathrm{b}}$} & 90.2 & 4 & 1.1 & 1.1 & .7 & 1.8 & 1.1 & 83.9 & 6.8 & 0 & 1.7 & 1.7 & 3.4 & 2.5 & 94.9 & 1.9 & 1.9 & .6 & 0 & .6 & 0 \\
\hline & (248) & (11) & (3) & (3) & (2) & (5) & (3) & (99) & (8) & (0) & (2) & (2) & (4) & (3) & (149) & (3) & (3) & (1) & (0) & (1) & (0) \\
\hline \multirow[t]{2}{*}{ Website/Blog ${ }^{\mathrm{b}}$} & 88.7 & 5.5 & 1.1 & 1.1 & .4 & 2.2 & 1.1 & 82.2 & 8.5 & 0 & 1.7 & .8 & 4.2 & 2.5 & 93.6 & 3.2 & 1.9 & .6 & 0 & .6 & 0 \\
\hline & $(244)$ & $(15)$ & (3) & (3) & (1) & (6) & (3) & (97) & $(10)$ & $(0)$ & (2) & (1) & (5) & (3) & $(147)$ & $(5)$ & (3) & (1) & $(0)$ & (1) & $(0)$ \\
\hline Demanded passwords ${ }^{b}$ & & & & & & & & & & & & & & & & & & & & & \\
\hline
\end{tabular}




\begin{tabular}{|c|c|c|c|c|c|c|c|c|c|c|c|c|c|c|c|c|c|c|c|c|c|}
\hline Phone call & 92.4 & 4.7 & 1.1 & .7 & .7 & .4 & 0 & 89.8 & 4.2 & 2.5 & 1.7 & 1.7 & 0 & 0 & 94.3 & 5.1 & 0 & 0 & 0 & .6 & 0 \\
\hline & $(254)$ & (13) & (3) & (2) & (2) & (1) & $(0)$ & (106) & (5) & (3) & (2) & (2) & $(0)$ & $(0)$ & (148) & (8) & $(0)$ & $(0)$ & $(0)$ & (1) & (0) \\
\hline Text message & 90.5 & 6.5 & .4 & 1.1 & .7 & .4 & .4 & 89 & 5.9 & .8 & 2.5 & 1.7 & 0 & 0 & 91.7 & 7 & 0 & 0 & 0 & .6 & .6 \\
\hline & (249) & (18) & (1) & (3) & (2) & (1) & (1) & (105) & (7) & (1) & (3) & (2) & $(0)$ & $(0)$ & (144) & (11) & $(0)$ & $(0)$ & $(0)$ & (1) & (1) \\
\hline Instant messenger & 92.7 & 4.4 & 1.1 & .7 & .4 & .7 & 0 & 90.7 & 4.2 & 2.5 & 1.7 & .8 & 0 & 0 & 94.3 & 4.5 & 0 & 0 & 0 & 1.3 & 0 \\
\hline & $(255)$ & (12) & (3) & (2) & (1) & (2) & $(0)$ & (107) & (5) & (3) & (2) & (1) & $(0)$ & $(0)$ & (148) & (7) & $(0)$ & $(0)$ & $(0)$ & (2) & (0) \\
\hline Social networking site & 91.3 & 6.2 & 1.1 & .7 & .4 & .4 & 0 & 90.7 & 5.1 & 1.7 & 1.7 & .8 & 0 & 0 & 91.7 & 7 & .6 & 0 & 0 & .6 & 0 \\
\hline & $(251)$ & (17) & (3) & (2) & (1) & (1) & (0) & (107) & (6) & (2) & (2) & (1) & (0) & $(0)$ & (144) & (11) & (1) & (0) & (0) & (1) & (0) \\
\hline Picture message & 95.6 & 1.8 & 1.5 & .4 & .4 & .4 & 0 & 93.2 & 1.7 & 3.4 & .8 & .8 & 0 & 0 & 97.5 & 1.9 & 0 & 0 & 0 & .6 & 0 \\
\hline & $(263)$ & $(5)$ & (4) & (1) & (1) & (1) & $(0)$ & (110) & (2) & (4) & (1) & (1) & $(0)$ & $(0)$ & (153) & (3) & $(0)$ & $(0)$ & $(0)$ & (1) & (0) \\
\hline Video chat & 95.6 & 2.2 & .4 & .7 & .7 & .4 & 0 & 93.2 & 3.4 & .8 & 1.7 & .8 & 0 & 0 & 97.5 & 1.3 & 0 & 0 & .6 & .6 & 0 \\
\hline & $(263)$ & (6) & (1) & (2) & (2) & (1) & $(0)$ & (110) & (4) & (1) & (2) & (1) & $(0)$ & $(0)$ & (153) & (2) & $(0)$ & $(0)$ & (1) & (1) & (0) \\
\hline Email & 95.3 & 2.5 & .4 & .7 & 1.1 & 0 & 0 & 92.4 & 3.4 & .8 & 1.7 & 1.7 & 0 & 0 & 97.5 & 1.9 & 0 & 0 & .6 & 0 & 0 \\
\hline & $(262)$ & (7) & (1) & (2) & (3) & $(0)$ & $(0)$ & (109) & (4) & (1) & (2) & (2) & $(0)$ & $(0)$ & (153) & (3) & $(0)$ & $(0)$ & (1) & $(0)$ & (0) \\
\hline Chatroom & 96 & 1.8 & .4 & .4 & .4 & .7 & .4 & 94.1 & 1.7 & .8 & .8 & .8 & .8 & .8 & 97.5 & 1.9 & 0 & 0 & 0 & .6 & 0 \\
\hline & (264) & (5) & (1) & (1) & (1) & (2) & (2) & (111) & (2) & (1) & (1) & (1) & (1) & (1) & (153) & (3) & (0) & (0) & (0) & (1) & (0) \\
\hline Website/Blog & 96 & 1.8 & 1.1 & 0 & .4 & .4 & .4 & 93.2 & 2.5 & 2.5 & 0 & .8 & 0 & .8 & 98.1 & 1.3 & 0 & 0 & 0 & .6 & 0 \\
\hline & $(264)$ & (5) & (3) & $(0)$ & (1) & (1) & (1) & (110) & (3) & (3) & $(0)$ & (1) & $(0)$ & (1) & (154) & (2) & $(0)$ & $(0)$ & $(0)$ & (1) & (0) \\
\hline \multicolumn{22}{|l|}{ Deleted contacts ${ }^{\mathrm{c}}$} \\
\hline Phone call & 83.9 & 8.8 & 2.2 & 1.5 & 2.2 & .7 & .7 & 83.8 & 6.8 & 2.6 & 3.4 & 1.7 & 0 & 1.7 & 84.1 & 10.2 & 1.9 & 0 & 2.5 & 1.3 & 0 \\
\hline
\end{tabular}




\begin{tabular}{|c|c|c|c|c|c|c|c|c|c|c|c|c|c|c|c|c|c|c|c|c|c|}
\hline & 230) & (24) & (6) & (4) & (6) & (2) & (2) & (98) & (8) & (3) & (4) & (2) & $(0)$ & (2) & (132) & (16) & (3) & (0) & (4) & (2) & (0) \\
\hline \multirow[t]{2}{*}{ Text message } & 81.4 & 11.3 & 2.2 & 1.5 & 1.8 & 1.1 & .7 & 82.1 & 8.5 & 2.6 & 2.6 & 1.7 & .9 & 1.7 & 80.9 & 13.4 & 1.9 & .6 & 1.9 & 1.3 & 0 \\
\hline & $(223)$ & $(31)$ & (6) & (4) & (5) & (3) & (2) & (96) & (10) & (3) & (3) & (2) & (1) & (2) & (127) & (21) & (3) & (1) & (3) & (2) & (0) \\
\hline \multirow[t]{2}{*}{ Instant messenger } & 85.4 & 8 & 2.9 & .7 & 1.1 & 1.1 & .7 & 82.1 & 8.5 & 4.3 & 1.7 & .9 & .9 & 1.7 & 87.9 & 7.6 & 1.9 & 0 & 1.3 & 1.3 & 0 \\
\hline & $(234)$ & $(22)$ & (8) & (2) & (3) & (3) & (2) & (96) & (10) & (5) & (2) & (1) & (1) & (2) & (138) & (12) & (3) & $(0)$ & (2) & (2) & (0) \\
\hline \multirow[t]{2}{*}{ Social networking site } & 82.5 & 9.5 & 2.6 & 1.5 & 2.6 & .7 & .7 & 80.3 & 7.7 & 3.4 & 3.4 & 2.6 & .9 & 1.7 & 84.1 & 10.8 & 1.9 & 0 & 2.5 & .6 & 0 \\
\hline & $(226)$ & $(26$ & (7) & (4) & (7) & (2) & (2) & (94) & (9) & (4) & (4) & (3) & (1) & (2) & $(132)$ & (17) & (3) & $(0)$ & (4) & (1) & (0) \\
\hline \multirow[t]{2}{*}{ Picture message } & 89.8 & 5.1 & 1.8 & 1.5 & 1.1 & 0 & .7 & 87.2 & 5.1 & 1.7 & 3.4 & .9 & 0 & 1.7 & 91.7 & 5.1 & 1.9 & 0 & 1.3 & 0 & 0 \\
\hline & $(246)$ & (14) & (5) & (4) & (3) & $(0)$ & (2) & (102) & (6) & (2) & (4) & (1) & (0) & (2) & $(144)$ & (8) & (3) & $(0)$ & (2) & $(0)$ & (0) \\
\hline \multirow[t]{2}{*}{ Video chat } & 92 & 3.3 & 2.2 & 1.5 & .4 & 0 & .7 & 88 & 3.4 & 3.4 & 3.4 & 0 & 0 & 1.7 & 94.9 & 3.2 & 1.3 & 0 & 6 & 0 & 0 \\
\hline & $(252)$ & (9) & (6) & (4) & (1) & $(0)$ & (2) & (103) & (4) & (4) & (4) & $(0)$ & $(0)$ & (2) & (149) & (5) & (2) & $(0)$ & (1) & $(0)$ & (0) \\
\hline \multirow[t]{2}{*}{ Email } & 91.6 & 3.6 & 1.5 & 1.5 & 1.1 & 0 & .7 & 88.9 & 3.4 & 1.7 & 3.4 & .9 & 0 & 1.7 & 93.6 & 3.8 & 1.3 & 0 & 1.3 & 0 & 0 \\
\hline & $(251)$ & (10) & (4) & (4) & (3) & $(0)$ & (2) & (104) & (4) & (2) & (4) & (1) & $(0)$ & (2) & (147) & (6) & (2) & $(0)$ & (2) & $(0)$ & (0) \\
\hline \multirow[t]{2}{*}{ Chatroom } & 92.7 & 2.9 & 2.2 & 1.1 & .4 & 0 & .7 & 88.9 & 3.4 & 3.4 & 2.6 & 0 & 0 & 1.7 & 95.5 & 2.5 & 1.3 & 0 & .6 & 0 & 0 \\
\hline & $(254)$ & (8) & (6) & (3) & (1) & $(0)$ & (2) & (104) & (4) & (4) & (3) & $(0)$ & (0) & (2) & $(150)$ & (4) & (2) & $(0)$ & (1) & $(0)$ & (0) \\
\hline \multirow[t]{2}{*}{ Website/Blog } & 92.3 & 2.9 & 1.5 & 1.5 & .7 & .4 & .7 & 88.9 & 3.4 & 1.7 & 3.4 & .9 & 0 & 1.7 & 94.9 & 2.5 & 1.3 & 0 & .6 & .6 & 0 \\
\hline & $(253)$ & (8) & (4) & (4) & (2) & (1) & (1) & (104) & (4) & (2) & (4) & (1) & $(0)$ & (2) & (149) & (4) & (2) & $(0)$ & (1) & (1) & (0) \\
\hline \multicolumn{22}{|l|}{ Afraid to respond ${ }^{c}$} \\
\hline \multirow[t]{2}{*}{ Phone call } & 90.5 & 7.3 & .7 & .7 & .4 & .4 & 0 & 93.2 & 5.1 & .9 & .9 & 0 & 0 & 0 & 88.5 & 8.9 & .6 & .6 & .6 & 6 & 0 \\
\hline & $(248)$ & (20) & (2) & (2) & (1) & (1) & $(0)$ & (109) & (6) & (1) & (1) & $(0)$ & $(0)$ & $(0)$ & (139) & (14) & (1) & (1) & (1) & (1) & (0) \\
\hline
\end{tabular}




\begin{tabular}{|c|c|c|c|c|c|c|c|c|c|c|c|c|c|c|c|c|c|c|c|c|c|}
\hline Text message & 86.9 & 10.6 & 1.1 & .4 & .7 & 0 & .4 & 90.6 & 6 & 1.7 & .9 & .9 & 0 & 0 & 84.1 & 14 & .6 & 0 & .6 & 0 & .6 \\
\hline & $(238)$ & (29) & (3) & (1) & (2) & $(0)$ & (1) & (106) & (7) & (2) & (1) & (1) & $(0)$ & $(0)$ & (132) & $(22)$ & (1) & $(0)$ & (1) & $(0)$ & (1) \\
\hline \multirow[t]{2}{*}{ Instant messenger } & 92.3 & 5.5 & 1.1 & .7 & 0 & .4 & 0 & 93.2 & 5.1 & .9 & .9 & 0 & 0 & 0 & 91.7 & 5.7 & 1.3 & .6 & 0 & .6 & 0 \\
\hline & $(253)$ & (15) & (3) & (2) & $(0)$ & (1) & $(0)$ & (109) & (6) & (1) & (1) & $(0)$ & $(0)$ & $(0)$ & (144) & (9) & (2) & (1) & $(0)$ & (1) & (0) \\
\hline \multirow[t]{2}{*}{ Social networking site } & 93.1 & 4.4 & 1.1 & 0 & .7 & .7 & 0 & 94 & 4.3 & .9 & 0 & .9 & 0 & 0 & 92.4 & 4.5 & 1.3 & 0 & .6 & 1.3 & 0 \\
\hline & $(255)$ & (12) & (3) & $(0)$ & (2) & (2) & $(0)$ & (110) & (5) & (1) & $(0)$ & (1) & $(0)$ & $(0)$ & (145) & (7) & (2) & $(0)$ & (1) & (2) & (0) \\
\hline \multirow[t]{2}{*}{ Picture message } & 96.4 & 2.2 & .7 & 0 & 0 & .7 & 0 & 94.9 & 4.3 & .9 & 0 & 0 & 0 & 0 & 97.5 & .6 & .6 & 0 & 0 & 1.3 & 0 \\
\hline & $(264)$ & (6) & (2) & $(0)$ & $(0)$ & (2) & $(0)$ & (111) & (5) & (1) & $(0)$ & $(0)$ & $(0)$ & $(0)$ & (153) & $(1)$ & (1) & $(0)$ & $(0)$ & (2) & (0) \\
\hline \multirow[t]{2}{*}{ Video chat } & 96.7 & 2.6 & 0 & .4 & 0 & .4 & 0 & 95.7 & 3.4 & 0 & .9 & 0 & 0 & 0 & 97.5 & 1.9 & 0 & 0 & 0 & .6 & 0 \\
\hline & $(265)$ & (7) & $(0)$ & (1) & $(0)$ & (1) & $(0)$ & (112) & (4) & $(0)$ & (1) & $(0)$ & $(0)$ & $(0)$ & (153) & (3) & $(0)$ & $(0)$ & $(0)$ & (1) & (0) \\
\hline \multirow[t]{2}{*}{ Email } & 97.4 & 1.8 & 0 & .4 & 0 & .4 & 0 & 95.7 & 3.4 & 0 & .9 & 0 & 0 & 0 & 98.7 & 6 & 0 & 0 & 0 & .6 & 0 \\
\hline & $(267)$ & (5) & $(0)$ & (1) & $(0)$ & (1) & $(0)$ & (112) & (4) & $(0)$ & (1) & $(0)$ & $(0)$ & $(0)$ & (155) & $(1)$ & $(0)$ & $(0)$ & $(0)$ & (1) & (0) \\
\hline \multirow[t]{2}{*}{ Chatroom } & 97.8 & 1.5 & .4 & 0 & 0 & .4 & 0 & 96.6 & 2.6 & .9 & 0 & 0 & 0 & 0 & 98.7 & .6 & 0 & 0 & 0 & .6 & 0 \\
\hline & $(268)$ & (4) & (1) & $(0)$ & $(0)$ & (1) & $(0)$ & (113) & (3) & (1) & $(0)$ & $(0)$ & $(0)$ & $(0)$ & (155) & (1) & $(0)$ & $(0)$ & $(0)$ & (1) & (0) \\
\hline \multirow[t]{2}{*}{ Website/Blog } & 97.4 & 1.8 & 0 & .4 & 0 & .4 & 0 & 96.6 & 2.6 & 0 & .9 & 0 & 0 & 0 & 98.1 & 1.3 & 0 & 0 & 0 & .6 & 0 \\
\hline & $(267)$ & (5) & $(0)$ & (1) & $(0)$ & (1) & $(0)$ & (113) & (3) & $(0)$ & (1) & $(0)$ & $(0)$ & $(0)$ & (154) & $(2)$ & $(0)$ & $(0)$ & $(0)$ & (1) & $(0)$ \\
\hline \multicolumn{22}{|l|}{ Prevention from using } \\
\hline \multicolumn{22}{|l|}{ technology ${ }^{\mathrm{c}}$} \\
\hline \multirow[t]{2}{*}{ Phone call } & 91.2 & 4.4 & 1.5 & 1.1 & .7 & .4 & .7 & 93.2 & 3.4 & 0 & 1.7 & 0 & 0 & 1.7 & 89.8 & 5.1 & 2.5 & .6 & 1.3 & .6 & 0 \\
\hline & $(250)$ & (12) & (4) & (3) & (2) & (1) & (2) & (109) & (4) & $(0)$ & (2) & $(0)$ & $(0)$ & (2) & (141) & $(8)$ & (4) & (1) & (2) & (1) & $(0)$ \\
\hline
\end{tabular}




\begin{tabular}{|c|c|c|c|c|c|c|c|c|c|c|c|c|c|c|c|c|c|c|c|c|c|}
\hline Text message & 89.8 & 5.8 & 1.1 & .7 & 1.5 & 0 & 1.1 & 92.3 & 3.4 & 0 & 1.7 & .9 & 0 & 1.7 & 87.9 & 7.6 & 1.9 & 0 & 1.9 & 0 & .6 \\
\hline & $(246)$ & (16) & (3) & (2) & (4) & $(0)$ & (3) & (108) & (4) & $(0)$ & (2) & (1) & $(0)$ & (2) & (138) & (12) & (3) & $(0)$ & (3) & $(0)$ & (1) \\
\hline \multirow[t]{2}{*}{ Instant messenger } & 92.7 & 3.3 & 1.5 & 1.1 & .4 & 0 & 1.1 & 93.2 & 2.6 & .9 & 1.7 & 0 & 0 & 1.7 & 92.4 & 3.8 & 1.9 & .6 & .6 & 0 & .6 \\
\hline & $(254)$ & (9) & (4) & (3) & (1) & $(0)$ & (3) & (109) & (3) & (1) & (2) & $(0)$ & $(0)$ & (2) & (145) & (6) & (3) & (1) & (1) & $(0)$ & (1) \\
\hline \multirow[t]{2}{*}{ Social networking site } & 91.2 & 4 & 1.5 & .4 & 1.8 & .4 & .7 & 92.3 & 1.7 & 1.7 & .9 & 1.7 & 0 & 1.7 & 90.4 & 5.7 & 1.3 & 0 & 1.9 & .6 & 0 \\
\hline & $(250)$ & (11) & (4) & (1) & (5) & (1) & (2) & (108) & (2) & (2) & (1) & (2) & $(0)$ & (2) & $(142)$ & (9) & (2) & $(0)$ & (3) & (1) & (0) \\
\hline \multirow[t]{2}{*}{ Picture message } & 94.2 & 1.8 & 1.5 & .4 & .7 & .7 & .7 & 92.3 & 2.6 & 2.6 & .9 & 0 & 0 & 1.7 & 95.5 & 1.3 & .6 & 0 & 1.3 & 1.3 & 0 \\
\hline & $(258)$ & (5) & (4) & (1) & (2) & (2) & (2) & (108) & (3) & (3) & (1) & $(0)$ & $(0)$ & (2) & $(150)$ & (2) & (1) & $(0)$ & (2) & (2) & (0) \\
\hline \multirow[t]{2}{*}{ Video chat } & 95.3 & 1.5 & .7 & .7 & .4 & .7 & .7 & 93.2 & 1.7 & .9 & 1.7 & .9 & 0 & 1.7 & 96.8 & 1.3 & .6 & 0 & 0 & 1.3 & 0 \\
\hline & $(261)$ & (4) & (2) & (2) & (1) & (2) & (2) & (109) & (2) & (1) & (2) & (1) & $(0)$ & (2) & $(152)$ & (2) & (1) & (0) & (0) & (2) & (0) \\
\hline \multirow[t]{2}{*}{ Email } & 95.6 & 1.8 & 0 & 1.1 & .4 & .4 & .7 & 92.3 & 2.6 & 0 & 2.6 & .9 & 0 & 1.7 & 98.1 & 1.3 & 0 & 0 & 0 & .6 & 0 \\
\hline & $(262)$ & (5) & $(0)$ & (3) & (1) & (1) & (2) & (108) & (3) & $(0)$ & (3) & (1) & $(0)$ & (2) & (154) & (2) & $(0)$ & (0) & (0) & (1) & (0) \\
\hline \multirow[t]{2}{*}{ Chatroom } & 96 & 1.5 & 1.1 & .4 & 0 & .4 & .7 & 93.2 & 1.7 & 2.6 & .9 & 0 & 0 & 1.7 & 98.1 & 1.3 & 0 & 0 & 0 & .6 & 0 \\
\hline & (263) & (4) & (3) & (1) & $(0)$ & (1) & (2) & (109) & (2) & (3) & (1) & (0) & $(0)$ & (2) & (154) & (2) & $(0)$ & (0) & (0) & (1) & (0) \\
\hline \multirow[t]{2}{*}{ Website/Blog } & 96 & 1.8 & .4 & .4 & .4 & .4 & .7 & 94 & 1.7 & .9 & .9 & .9 & 0 & 1.7 & 97.5 & 1.9 & 0 & 0 & 0 & .6 & 0 \\
\hline & (263) & (5) & (1) & (1) & (1) & (1) & (2) & (110) & (2) & (1) & (1) & (1) & $(0)$ & (2) & (153) & (3) & $(0)$ & (0) & (0) & (1) & (0) \\
\hline
\end{tabular}

Note: *(N) Never; (O) Once; (M) Monthly; (F) fortnightly; (W) Weekly; (D) Daily; (H) Hourly; ${ }^{\mathrm{a}} 276$ respondents; ${ }^{\mathrm{b}} 275$ respondents; ${ }^{\mathrm{c}} 274$ respondents 